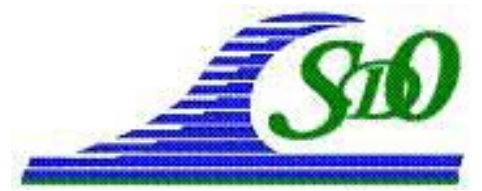

XI ${ }^{\text {èmes }}$ Journées Nationales Génie Côtier - Génie Civil

Les Sables d'Olonne, 22-25 juin 2010

DOI:10.5150/jngcgc.2010.091-V @ Editions Paralia CFL

disponible en ligne - http://www.paralia.fr - available online

\title{
Methodologies for assessing the wave energy resource near the coast: past and future
}

\author{
Cesar VIDAL PASCUAL ${ }^{1}$
}

1. Instituto de Hidráulica Ambiental de Cantabria. Avda de los Castros s/n, 39005, Santander, España.

vidalc@unican.es

\begin{abstract}
:
In this paper, first a historical revision of the data bases and computation methods applied for the analysis of wave energy resource is carried out and then the methodology used by the Institute of Environmental Hydraulics of Cantabria (IH Cantabria) to create the Spanish Atlas of Wave Energy Resource, funded by the Instituto para la Diversificación y el Ahorro de la Energía (IDAE), within the Spanish Renewable Energy Plan 2011-2020, is presented.
\end{abstract}

\section{Keywords:}

Wave databases - Spanish Atlas of Wave Energy Resource

\section{Résumé :}

Cet article passe tout d'abord en revue les méthodes historiques de constitution des bases de données et les méthodes informatiques appliquées à l'analyse des ressources énergétiques liées aux vagues océaniques. Il présente ensuite les méthodes utilisées par l'Institut d'Hydraulique Environnemental Cantabrique (IH Cantabria) pour réaliser l'Atlas Espagnol des Ressources liées à l'Energie des Vagues qui a été financé par l' Instituto para la Diversificatión y el Ahorro de la Energia (IDAE) dans le cadre du plan espagnol 2011-2020 des Energies Renouvelables.

\section{Mots-clés :}

Energie marine - Vagues - Base de données - Littoral espagnol

\section{Introduction}

By the end of the 1970s and during the beginning of the 1980s, the oil crisis pressed the energy companies and the governments to invest in the study of wave resources and in the development of techniques for its use. By then, the existing information on wave characteristics around the coasts was mainly based on two data sources: instrumental data obtained by meteorological ships, and a few scalar wave buoys and visual wave data, collected by human observers aboard voluntary observing ships (VOS) cruising around the world. With this information, the first maps of wave energy resource were drawn as shown in figure 1 for the coasts of the Iberian Peninsula, taken from VIDAL PASCUAL (1986). 
This effort slowed down markedly in the 1990s, due to the drop in oil prices and the evident difficulties (and consequent costs) of the wave energy conversion. Nevertheless, during the first decade of this century, the crisis of the energy system based on the limited amount of fossil resources and the environmental problems derived from their use has impelled the renewable energies in general and wave energy in particular. When the new studies of wave resource were undertaken the great qualitative step carried out on the available information and computation capacity was evident. Today, wave resource analysis can be carried out at a resolution and level of precision unthinkable three decades ago.
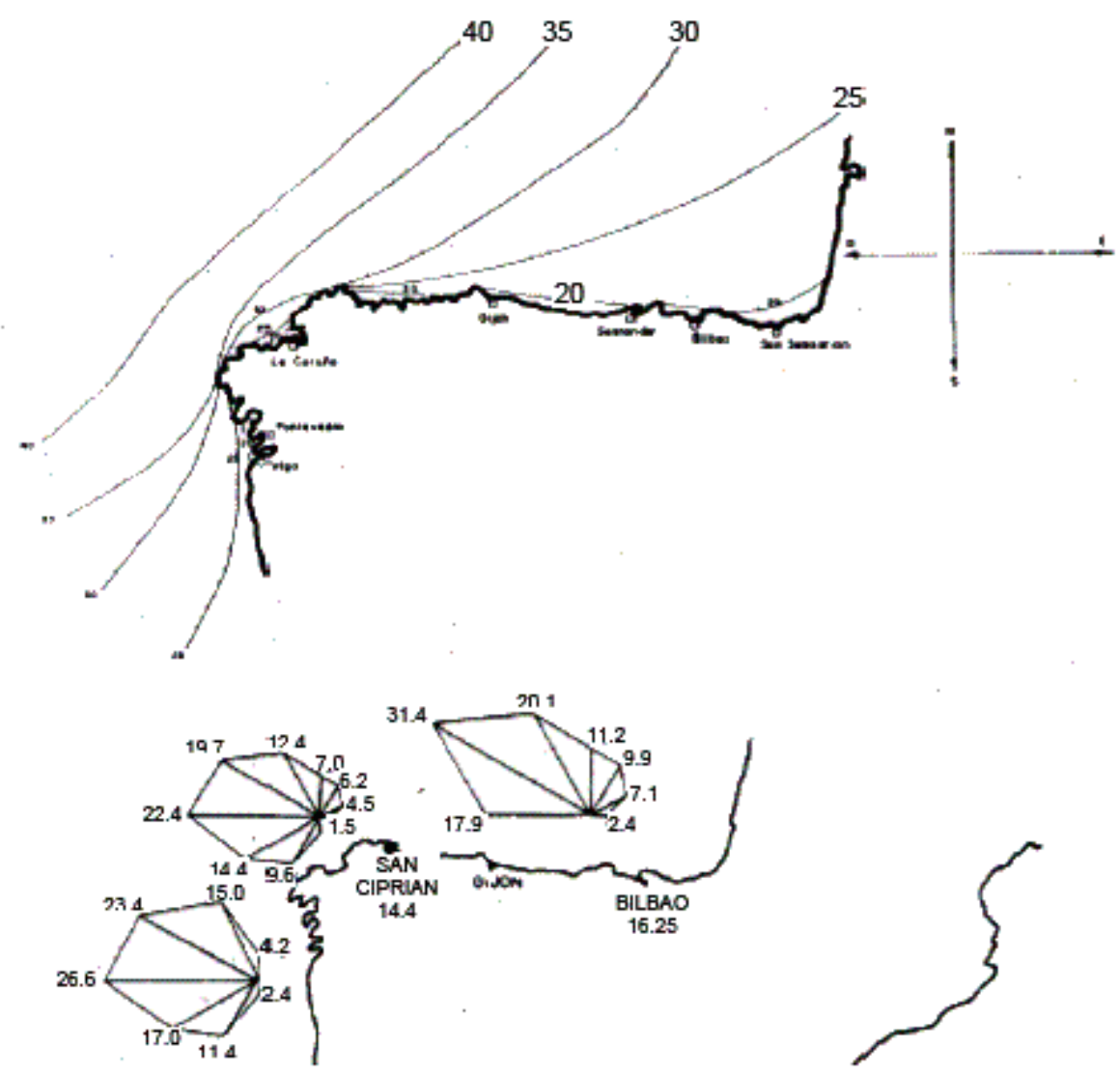

Figure 1. Annual mean wave energy flux $(\mathrm{kW} / \mathrm{m})$ in North Spain coastal waters.

Source: VIDAL PASCUAL (1986).

\section{History of wave energy resource computation}

\subsection{Wave data sources : instrumental data}

\subsubsection{Data buoys}

Instrumental data were very scarce in the 1970s. Most wave buoys were scalar (without directional information) and installed in intermediate waters. Time series of sea state 


\section{XI $I^{\text {èmes }}$ Journées Nationales Génie Côtier - Génie Civil}

Les Sables d'Olonne, 22-25 juin 2010

parameters were generally very short because the installation began in that decade. As an example, the first wave buoy of the Wave Record and Measurement Network (REMRO) installed by the Organismo Público Puertos del Estado (OPPE) was anchored in 1976, at a depth of 35 m outside Punta Lucero breakwater, in the entrance of Bilbao Port.

Although the length of the wave parameters time series provided by the scalar buoys has (logically) been increasing over time, the quality of the information supplied suffers from the shortcomings associated to the water depth and lack of directional information. For that reason, at the end of the 1980s, directional buoys in deep water were installed. In the OPPE deep water buoys network, the first directional buoy was anchored in 1990. Another shortcoming of the instrumental data based on wave buoys is that derived from interruption due to breakdowns and the necessary maintenance operations. Another factor to take into consideration is the high maintenance cost, responsible for a relatively broad spatial resolution.

Due to their inherent quality and also taking into account their limitations, directional wave buoy data are very suitable for calibration and validation of non-instrumental wave data bases, such as visual or atmospheric reanalysis wave data (which appeared in the 1990s). The quality of wave data base propagation to intermediate or shallow waters can be validated using data from the scalar coastal wave buoys.

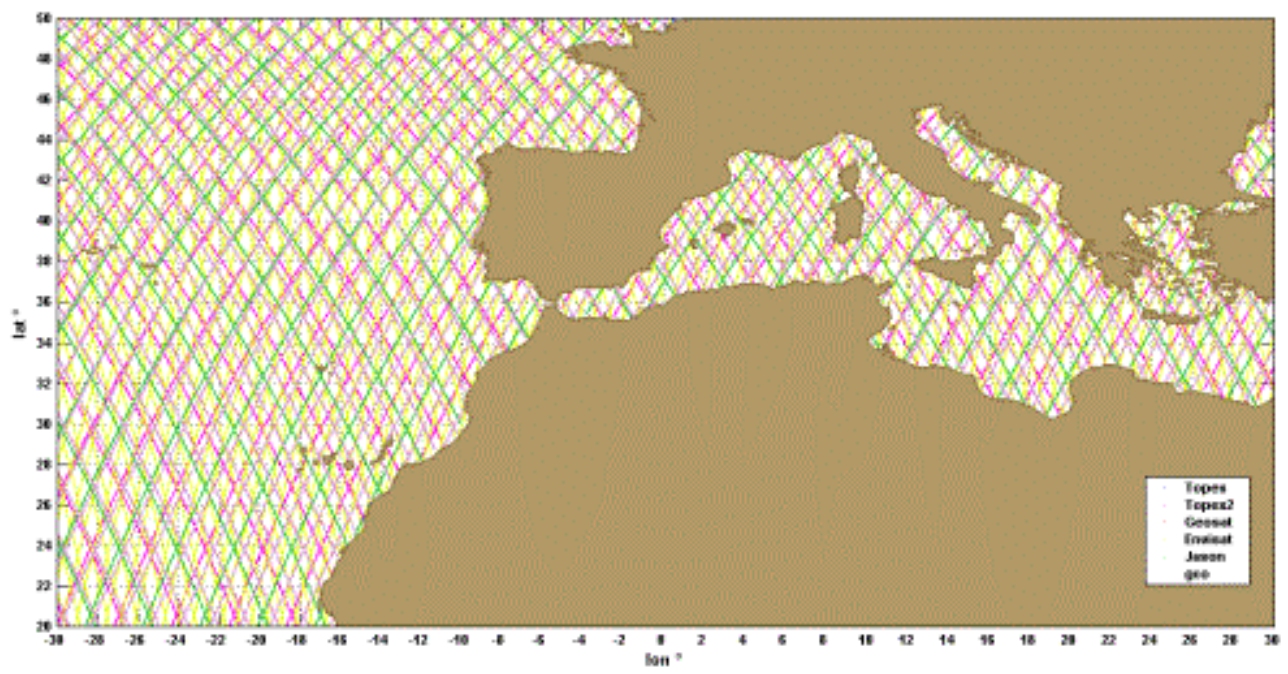

Figure 2. Spatial distribution of several satellite wave data bases in the North Atlantic and Mediterranean basins.

\subsubsection{Satellite wave data}

The only source of instrumental information that provides a global scope is facilitated by satellites with radar altimeters that can determine wave parameters such as $\mathrm{H}_{\mathrm{m} 0}$ with errors similar to those provided by wave buoys, CAIRES \& STERL (2003). Figure 2 


\section{Thème 6 - Energies marines}

shows the spatial distribution of several satellite wave data bases covering the North Atlantic and Mediterranean basins.

The main problem with satellite wave data is the spatial and temporal resolution. Satellites orbit the globe in a fixed trajectory, lasting 10 to 15 days between two consecutives passes over the same point, which is why satellite wave data are very suitable for wave mean regimes or for calibration of non-instrumental wave data, but not appropriate to describe extreme wave regimes.

\subsubsection{Visual wave data}

Sailors face many hazards - storms, rough seas, ice and icebergs. As early as 1853, this reality led seafaring nations to organize the first formal international meteorological meeting to coordinate weather observations at sea. Ever since, meteorological observations taken from ships have provided essential inputs to weather warnings and forecasts, which have become progressively more accurate. The World Meteorological Organization (WMO) and the Intergovernmental Oceanographic Commission (IOC) of the United Nations Educational, Scientific and Cultural Organization (UNESCO) have been working with the maritime community to enhance voluntary observational programmes carried out by ships at sea. Worldwide Voluntary Observing Ships (VOS) numbers reached a peak of about 7700 ships in 1984-85 but have since declined, with only 6700 vessels from 52 countries participating in early 2000 . This decline reflects the continuing trend towards fewer but larger ships but has been balanced, to some extent, by the fact that vessels, in general, now spend less time in port. This fact, in addition to improved communications via satellite, has actually led to enhancements in both the quantity and the quality of meteorological reports received from the VOS.

Many of the data on meteorological and oceanic conditions provided by the VOSs are instrumental (atmospheric pressure, air and water temperature, wind speed and direction, etc.). Unfortunately, to measure wave data using instruments aboard a cruising ship is not a cheap or easy task, and most of the wave data from the VOS is obtained by human observers aboard. Visual data comprises wave height, period and direction from the SEA and SWELL components.

Visual data suffers from shortcomings due to the subjectivity of the data acquisition and from the lack of spatial and temporal uniformity, see figure 3. Also, these data are poor in the extreme wave heights, because seafarers try to change the ships route to avoid the highest storms.

Until the 1990s, visual data were the only global data source of directional wave data and there are many studies focusing on calibrations of these data using instrumental wave data from buoys, such as those of HOGBEN and LUMB (1967) and JARDINE (1979). 


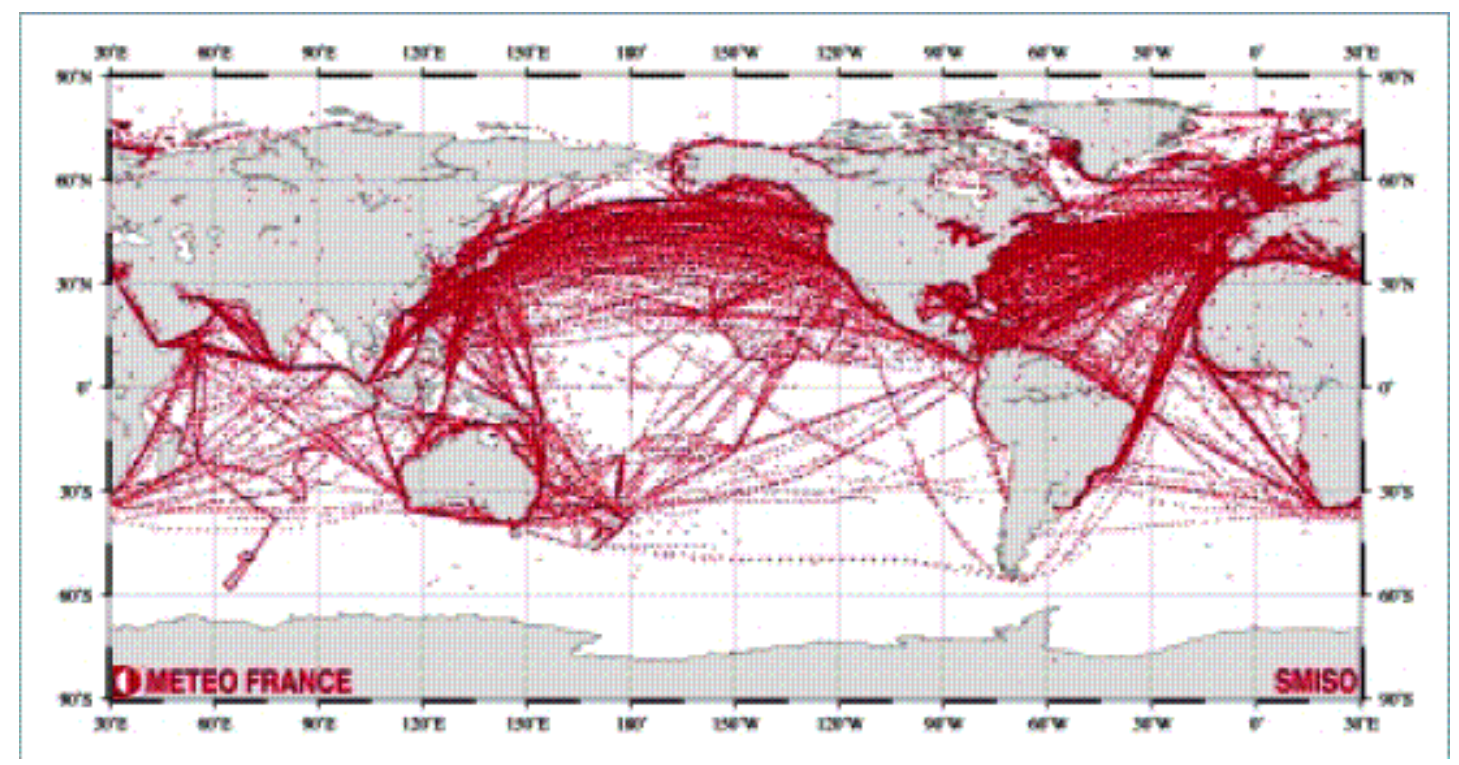

Figure 3. Position of VOS data points taken around de Globe in August 2000.

Source: WMO.

Since the appearance of the atmospheric reanalysis wave data bases, visually obtained wave data has lost importance, although VOS data is still a main source of atmospheric and oceanographic instrumental data

\subsubsection{Wave data bases from atmospheric reanalysis}

By the end of the 1990s, numerical wave generation models started to be massively applied, coupled with atmospheric reanalysis data to generate historical wave data bases, for example, the Waves and Storms in the North Atlantic (WASA), founded by the European Union's Environmental Program, or the WANA project founded by the OPPE's Maritime Program. At present, the OPPE reanalysis wave data base for Spanish waters is SIMAR-44, based on the European Project HIndcast of dynamic Processes of the Ocean and Coastal AreaS of Europe (HIPOCAS), SOARES et al. (2002).

The most currently used atmospheric reanalysis databases are: (1) ERA-40 from 1957 to 2002, (2) ERA-Interim, from 1989 to present, both (1) and (2) carried out by the European Centre for Medium-Range Weather Forecasts (ECMWF), (3) Japan Meteorological Agency (JMA) and (4) NCEP/NCAR Reanalysis Project, carried out by the National Center for Environmental Prediction (NCEP) and the National Center for Atmospheric Research (NCAR). NCEP/NCAR is one the most time-expanded global reanalysis systems, while the ERA-Interim and the JRA-25 are the global reanalysis with better instrumental data assimilation using satellite information. In some areas where the global data bases lack spatial resolution (such as in the Mediterranean), dynamic downscaling is used to improve resolution. 
IH CANTABRIA (2010) has recently concluded the creation of a global wave reanalysis data base using two independent atmospheric reanalysis data bases, validated with satellite data:

I. Global atmospheric reanalysis NCEP/NCAR 1:

Average wind speed and direction at $10 \mathrm{~m}$ over the sea surface and atmospheric pressure at sea level, from 1948 to 2009. Temporal resolution of $6 \mathrm{~h}$. Spatial resolution of $\sim 1.875^{\circ}$ (Gaussian mesh T62).

II. Regional atmospheric reanalysis (Mediterranean and Cadiz Gulf) SeaWind 2, generated by the IH Cantabria:

Average wind speed and direction at $10 \mathrm{~m}$ over the surface and atmospheric pressure at sea level, from 1989 to 2009 . Temporal resolution of $1 \mathrm{~h}$. Spatial resolution of $\sim 15$ $\mathrm{km}$ (Lambert conical projection mesh).

Once the atmospheric reanalysis is obtained, a wave generation model is applied to generate the wave data base. In the case of IH Cantabria, the WaveWatch III (TOLMAN, 1997; 1999) is used. The generated wave data base has the following general characteristics: (1) homogeneous spatial resolution along the coasts with a 10$15 \mathrm{~km}$ separation between nodes; (2) temporal resolution of $1 \mathrm{~h}$; (3) storage of spectral sea state parameters $\left(H_{s}, T_{m}, T_{p}, \theta_{m}\right)$ as well as the directional spectra components $S(\omega, \theta)$, along the coast; (4) long data series (60 years global) and 20 years for the Mediterranean, that provide a good statistical description and (5) updatable databases in which one can incorporate new registers.

Particularly, the two reanalysis data bases generated by IH Cantabria have the following characteristics:

- GOW 1.0 (Global Ocean Waves 1.0). Hourly reanalysis for the period between 19482008, with $1^{\circ} \times 1.5^{\circ}$ global coverage and $0.1^{\circ} \times 0.1^{\circ}$ along the Spanish coasts. Atmospheric forcing taken from the NCEP/NCAR IH Cantabria reanalysis.

- GOW 2.1 (Global Ocean Waves 2.1). Hourly reanalysis for the period between 19892008 with $0.125^{\circ}$ resolution in the Mediterranean and Cádiz Gulf. Atmospheric forcing taken from the dynamic downscaling SeaWind with a $15 \mathrm{~km}$ spatial resolution, nested with the atmospheric reanalysis ERA-Interim. In the West boundary the hourly directional spectra taken from the GOW 1.0 reanalysis are introduced.

These wave data bases have been validated using information from World Ocean wave buoys. Figure 4 shows a comparison between the $\mathrm{H}_{\mathrm{m} 0}$ wave height measured by the NOAA 46005 buoy (Pacific) and the $\mathrm{H}_{\mathrm{m} 0}$ computed in the GOW 1.0 reanalysis. Although the validation carried out shows the good quality of the reanalysis data bases, before a propagation of these data bases can be made to the coast a directional calibration with satellite wave data will be carried out. This process will be shown in the methodology described in the following paragraphs. 

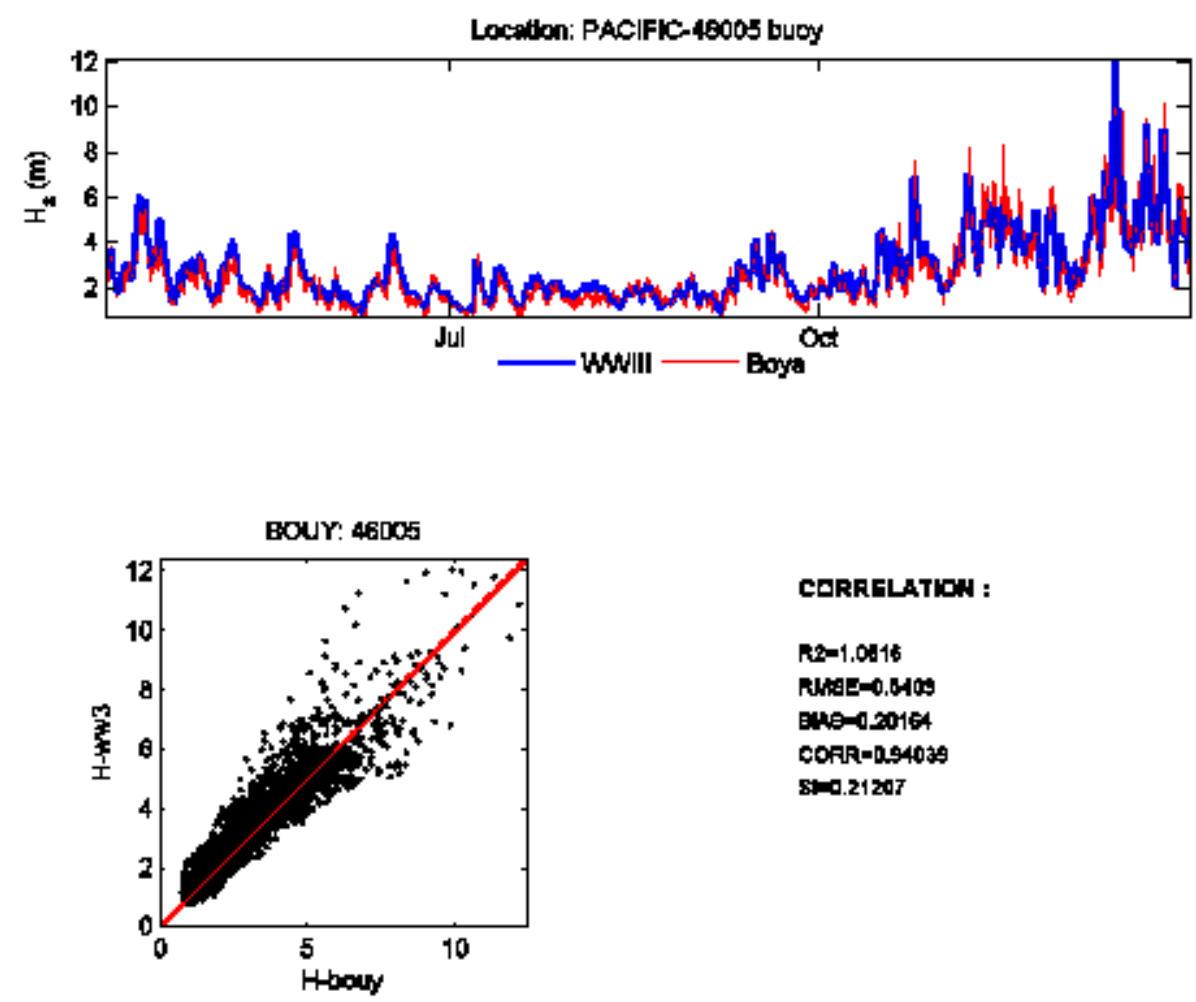

CERRELATIN :

$R 2=1.0416$

RNASE-0.600

Bute-0.0164

COFR=0.94030

$\sin 0.21207$

Figure 4. Validation of GOW 1.0 reanalysis wave data using NOAA 46005 wave buoy.

\section{Bathymetry and sea level data}

The first wave resource studies carried out in the 1970s used visual wave data, taken mostly in deep waters. Before the development of numerical wave propagation models, a systematic propagation of the wave data bases in intermediate and shallow waters was an impossible task and the wave resource in intermediate and shallow waters could only be calculated at specific points after a considerable effort. The development of numerical models of wave propagation made the systematic propagation of wave data bases to the coast an affordable task. Information of sea bed bathymetry and sea level fluctuations are necessary to obtain the water depth assigned to each propagated sea state.

\subsection{Bathymetry data}

At present, there are global bathymetry data bases, such as the General Bathymetric Chart of the Oceans (GEBCO), with 1' resolution provided by the British Oceanographic Data Centre (BDOC). This data base contains a combination of tested quality data coming from echo sounders and satellite. Besides these global data, nautical charts provide detailed bathymetric data near the coast, complementing the global information. 
Thème 6 - Energies marines

\subsection{Sea level data}

Sea level fluctuations are measured using tide gauges. In Spain, the OPPE manages a tide gauge network (REDMAR) installed in the main ports and operating since 1992. Other tide gauge data bases, managed by regional governments, as the Xarxa d'Instruments Oceanogràfics i Meteorològics (XION) of the Catalunya Generalitat, are also available.

\section{The methodology applied for the Spanish Atlas of Wave Energy Resource}

Over the last years, IH Cantabria has been working on the development of a methodology for calculating wave energy resources along the coasts where water depth influences wave propagation (CAMUS et al., 2007 and 2009; CAMUS, submitted). One application of this methodology is the creation of the Spanish Atlas of Wave Energy Resource under a project funded by the IDAE. The methodology, described in figure 5 , begins with the creation of a deep water reanalysis wave data base.

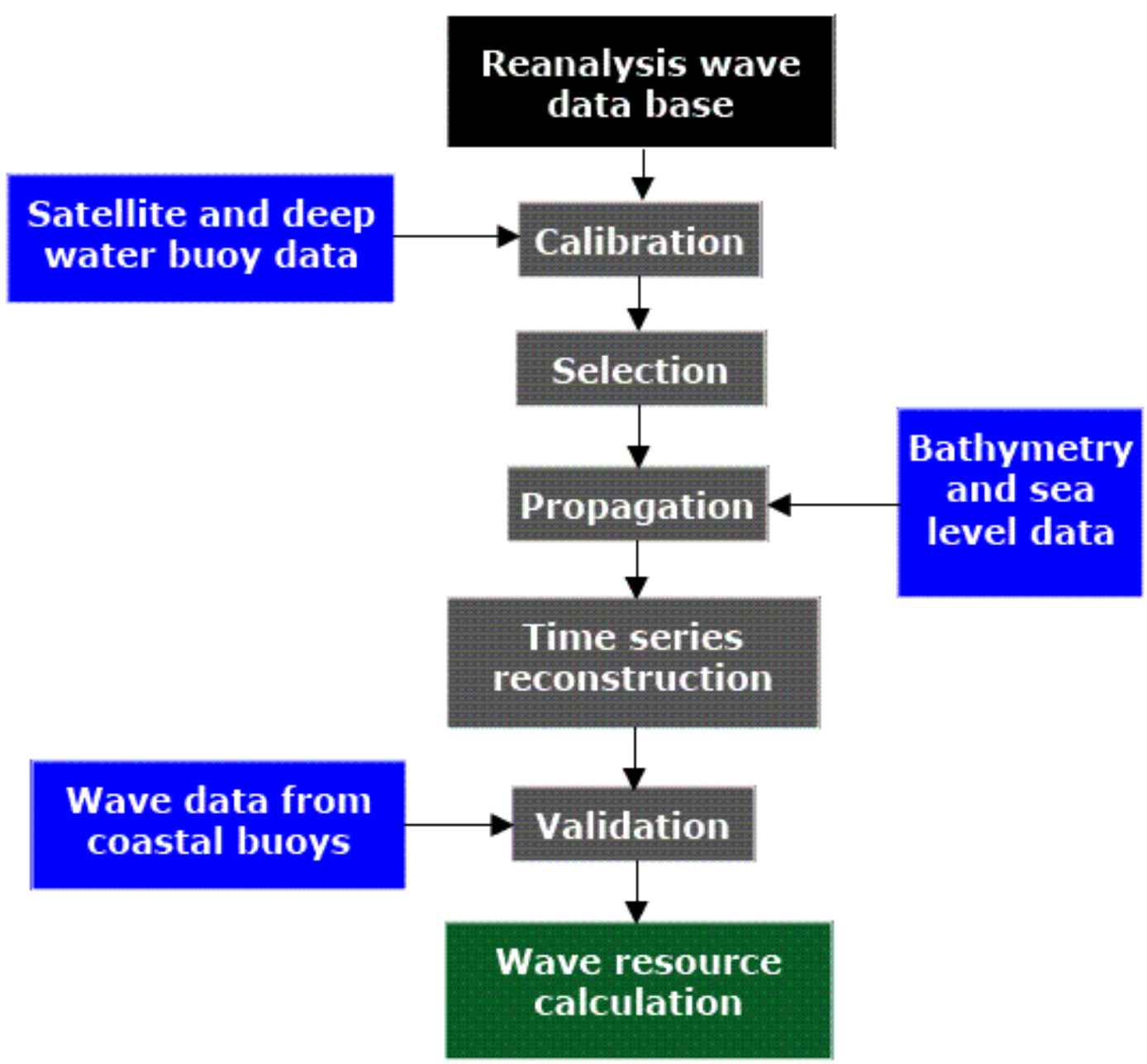

Figure 5. IH Cantabria general procedure to characterize wave energy resource in intermediate or shallow waters. 
The wave data of the nodes located in the external boundary of the propagation mesh are calibrated using satellite and deep water directional wave buoy data. After the calibration process, a technique is used to select a set of sea states that represent the full data base. These selected sea states are then propagated to the coast, using an appropriate wave propagation model and the characteristics of the propagated sea states are obtained in all the nodes of the propagation mesh. After propagation, the full data base is rebuilt at each propagation node using a multilinear interpolation technique. After validation with data from the coastal wave buoys, this propagated data base is used to define the statistics of wave parameters, including wave power parameters, in all selected points of the propagation mesh. In the next paragraphs the steps of this methodology are detailed.

\section{Calibration and validation of the reanalysis wave data base in the deep water boundary of the propagation mesh}

Reanalysis wave data bases show discrepancies with instrumental wave data that can be corrected by an appropriate calibration. To develop the Atlas this calibration has been carried out in each deep water boundary node point of the propagation meshes. Figure 6 shows all the points that have been calibrated. In the figure, red points are those belonging to the GOW 1.0 reanalysis and blue points are those of the GOW 2.1.

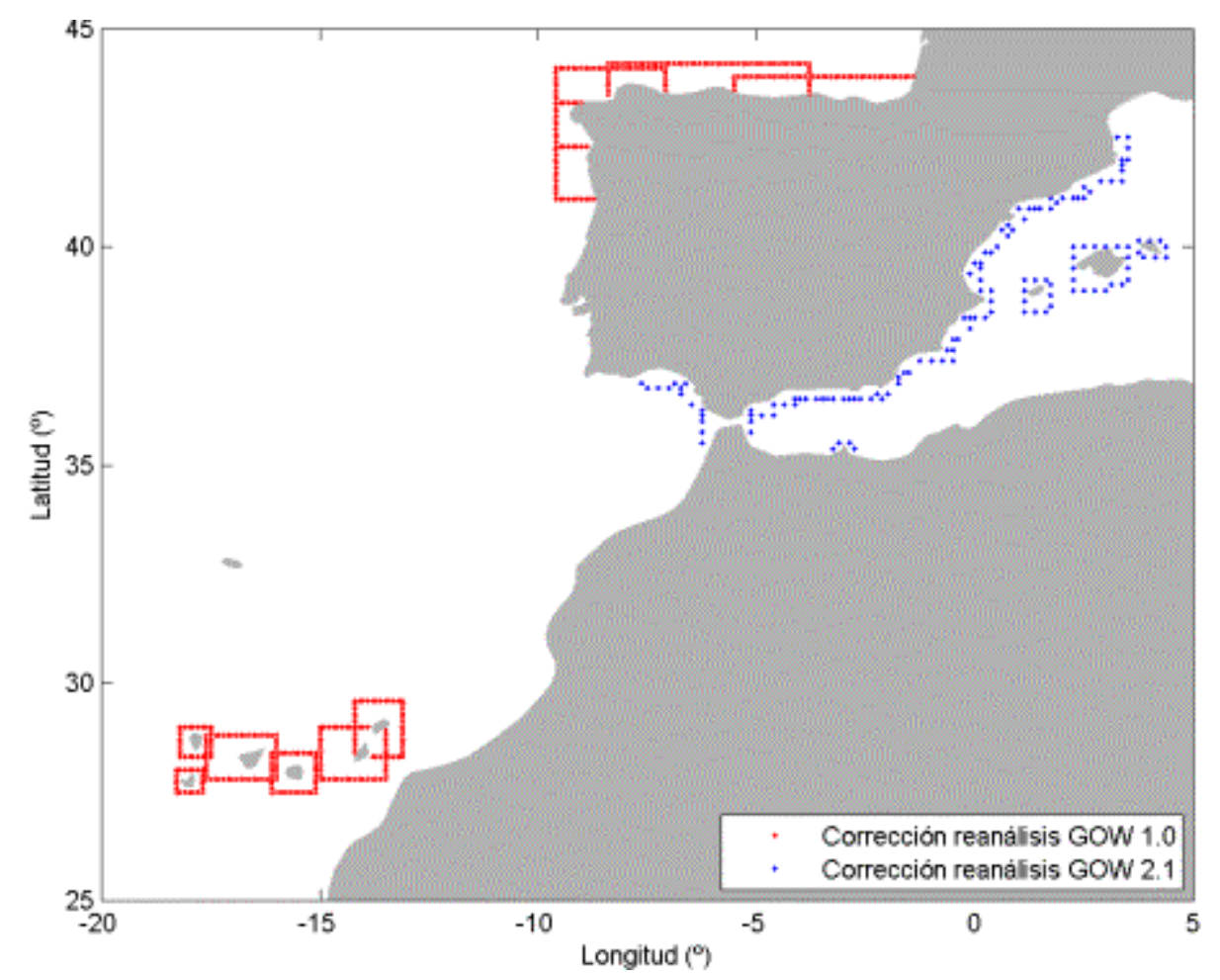

Figure 6. Calibrated points. 
To carry out the calibration, satellite wave data points located in an area around the reanalysis node point are used. This area is based on a criterium of rays thrown from the calibration node point, eliminating those satellite data that may be shielded by the coastline. For the Atlantic nodes a $1.5^{\circ}$ radius area has been selected, while for the Mediterranean, due to the higher spatial variability, the selected radius is $1^{\circ}$. Figure 7 shows the location of satellite data points selected for a node in the Cantabrian Sea and other in the Mediterranean near the island of Ibiza.

Once the area of satellite data points has been selected, the next calibration step consists in extracting from the GOW data base the wave parameters $\left(\mathrm{H}_{\mathrm{m} 0}, \theta_{\mathrm{m}}\right)$ corresponding in time with each satellite data. Consequently, a set of $\mathrm{N}$ data, defined as $\left\{\mathrm{H}_{\mathrm{m} 0 \text {,sat }}(\mathrm{i}), \mathrm{H}_{\mathrm{m} 0, \mathrm{GOW}}(\mathrm{i}), \theta_{\mathrm{m}, \mathrm{GOw}}(\mathrm{i})\right\}$ is obtained. From this set, a directional calibration of the $\mathrm{H}_{\mathrm{m} 0}$ wave height parameters is carried out.

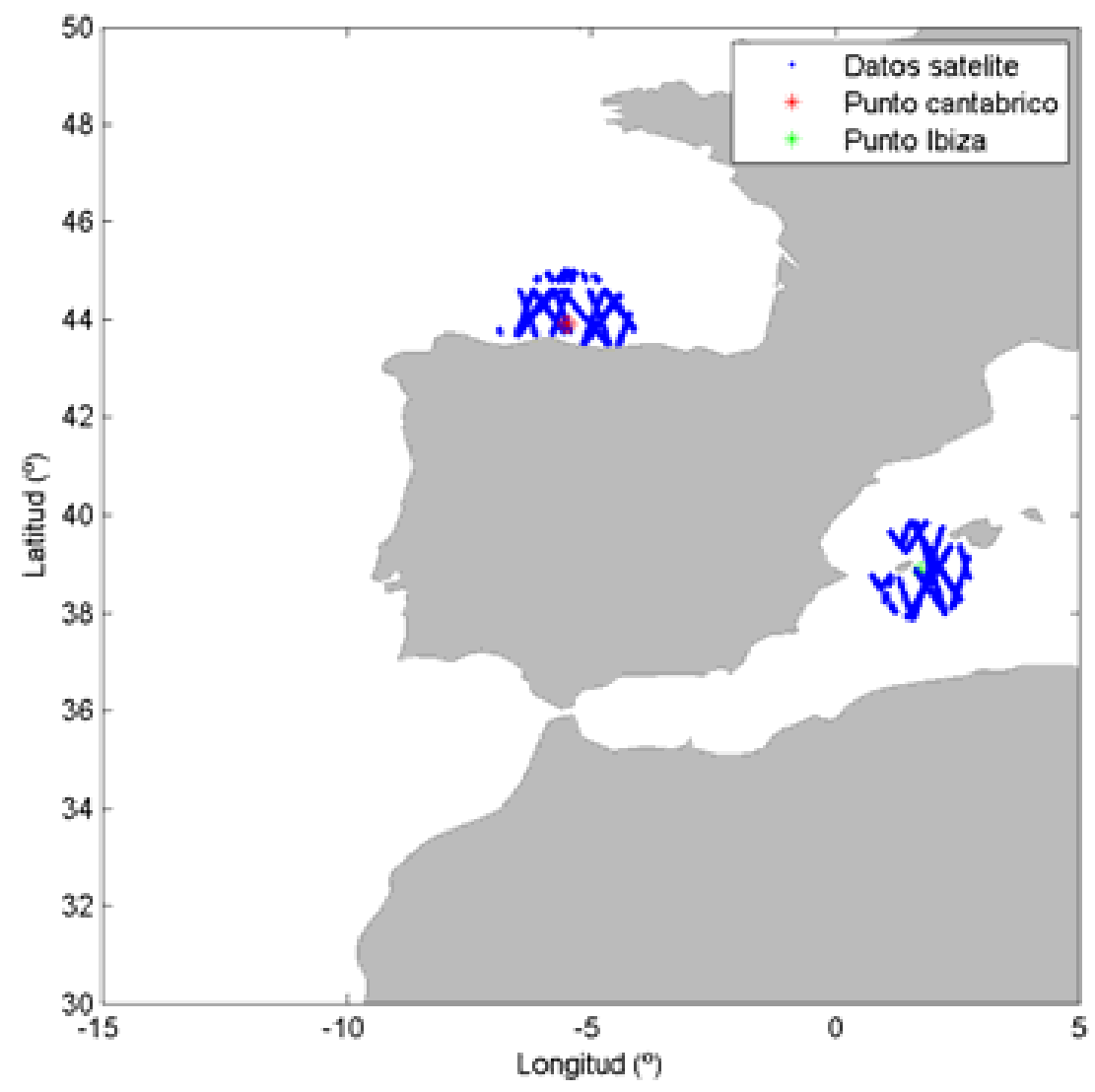

Figure 7. Satellite wave data points used for calibration of reanalysis wave data in two GOW node points located in the Cantabrian sea (red point) and in the Mediterranean, near the Ibiza Island (green point).

After the set of $\mathrm{N}$ data $\left\{\mathrm{H}_{\mathrm{m} 0 \text {,sat }}(\mathrm{i}), \mathrm{H}_{\mathrm{m} 0 \text {,GOw }}(\mathrm{i}), \theta_{\mathrm{m}, \mathrm{GOw}}(\mathrm{i})\right\}$ is obtained, it is clustered by $22.5^{\circ}$ sectors and a quantile-quantile fit is carried out using 20 quantiles equispaced in the Gumbel scale of maxima. The objective of this discretization is to give a similar 
weight to all data in all the different ranges of wave heights, in such a way that the lower wave heights, much more frequent in the wave regime, do not mask the storms. The equations selected for the fit are:

$\mathrm{H}_{\mathrm{m}, \mathrm{c}}= \begin{cases}\mathrm{a}(\theta) \mathrm{d}(\theta)^{\mathrm{b}(\theta)-1} \mathrm{H}_{\mathrm{m} 0} & \text { si } \mathrm{H}_{\mathrm{m} 0} \leq \mathrm{d}(\theta) \\ \mathrm{a}(\theta) \mathrm{H}_{\mathrm{m} 0}^{\mathrm{b}(\theta)} & \text { si } \mathrm{H}_{\mathrm{m} 0}>\mathrm{d}(\theta)\end{cases}$

where $H_{m 0, c}$ is the corrected zero-moment wave height, $H_{m 0}$ is the reanalysis zeromoment wave height, $a(\theta)$ and $b(\theta)$ are coefficients that depend on the wave direction and $\mathrm{d}(\theta)$ is the wave height under which the calibration is linear. Figure 8 shows an example of calibration of a GOW point in the Cantabrian sea where a total of 31263 pairs of satellite-GOW data have been used. The improvement obtained in this point with the calibration can be appreciated in figure 9 .

Figure 10 shows validation of the calibration using 5 directional deep water wave buoys in the Northwest of Spain: Bilbao, Cabo Peñas, Estaca de Bares, Villano-Sisargas and Silleiro. The 2007 time series for $\mathrm{H}_{\mathrm{m} 0}\left(\mathrm{H}_{\mathrm{s}}\right)$ are shown. Buoy data are drawn in green, GOW without calibration in blue and GOW with calibration in red. On the right hand side of the figure, the dispersion plots are also shown.

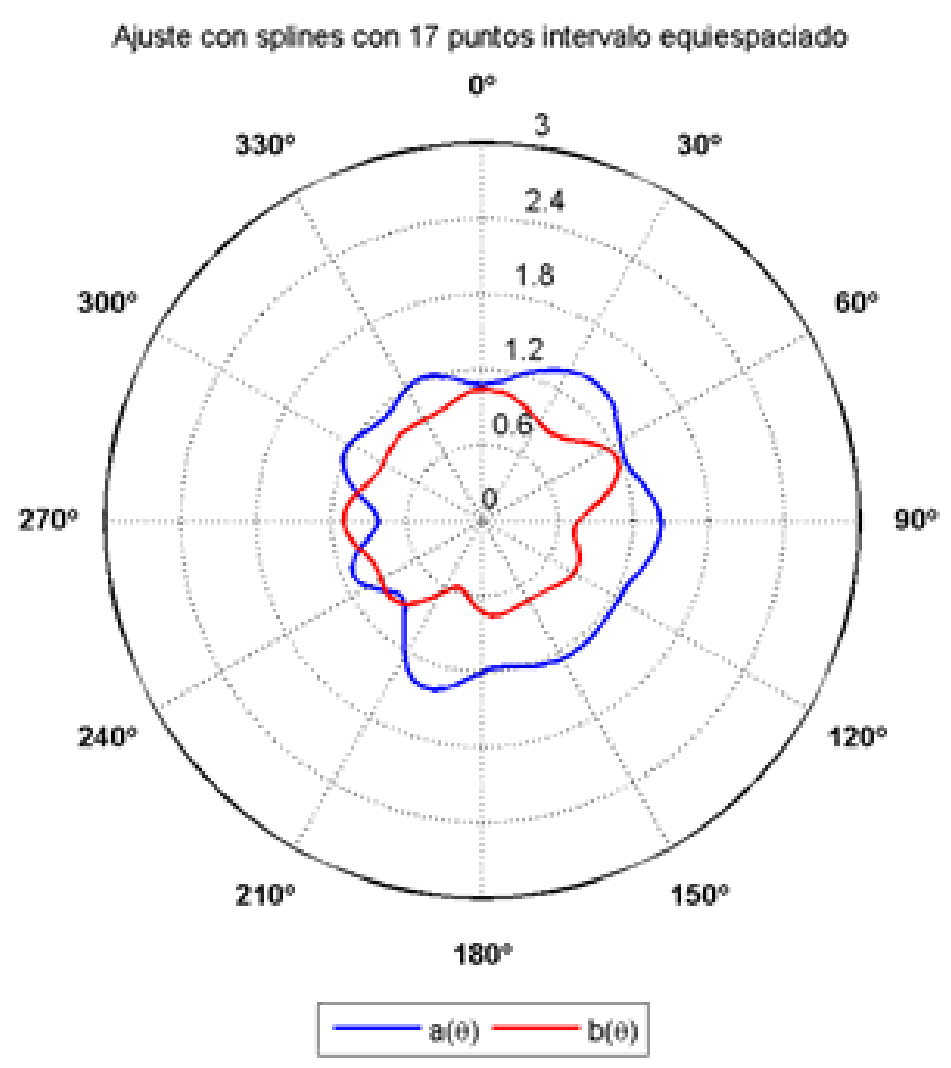

Figure 8. Calibration rose for $H_{m 0}$ obtained for a GOW point in the Cantabrian Sea. 
Thème 6 - Energies marines

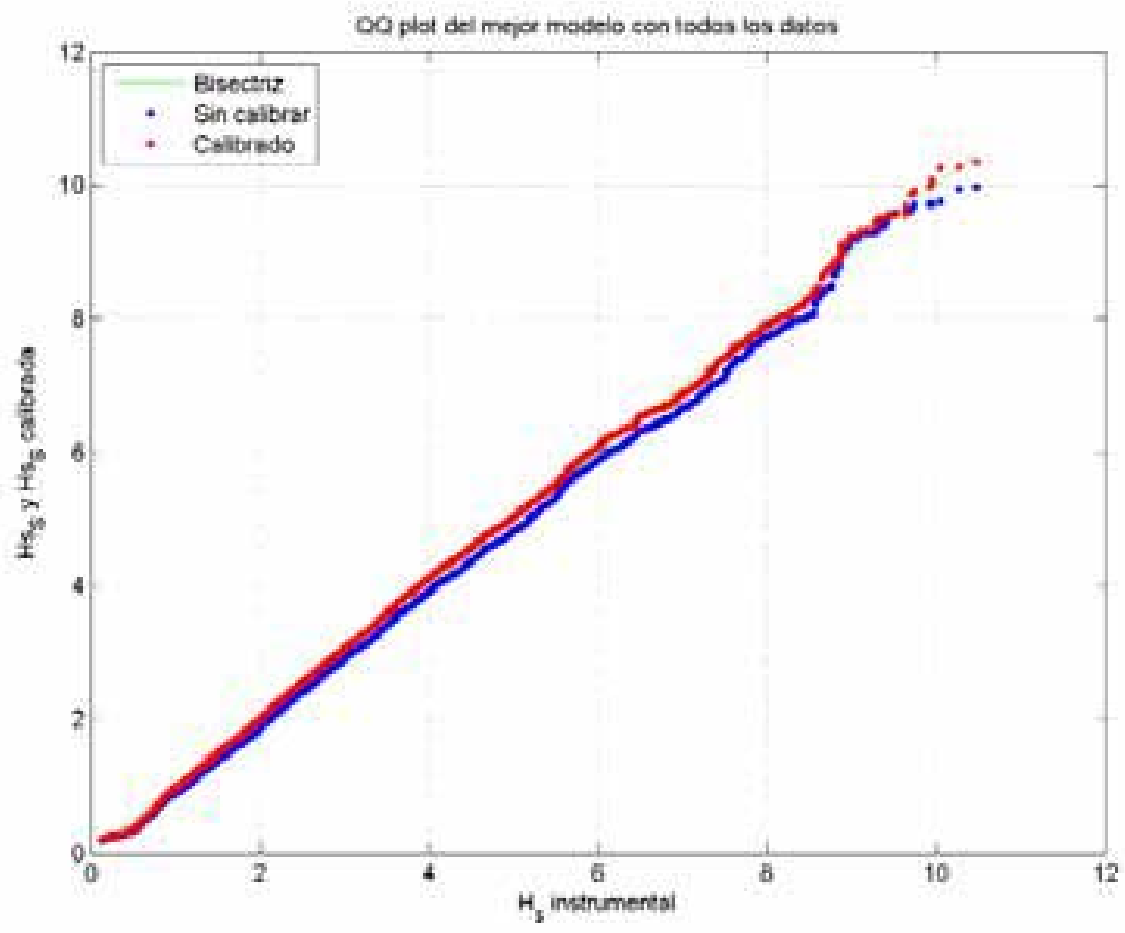

Figure 9. QQplot diagram with instrumental wave height (satellite) versus calibrated GOW with and without calibration. GOW point in the Cantabrian SEA.
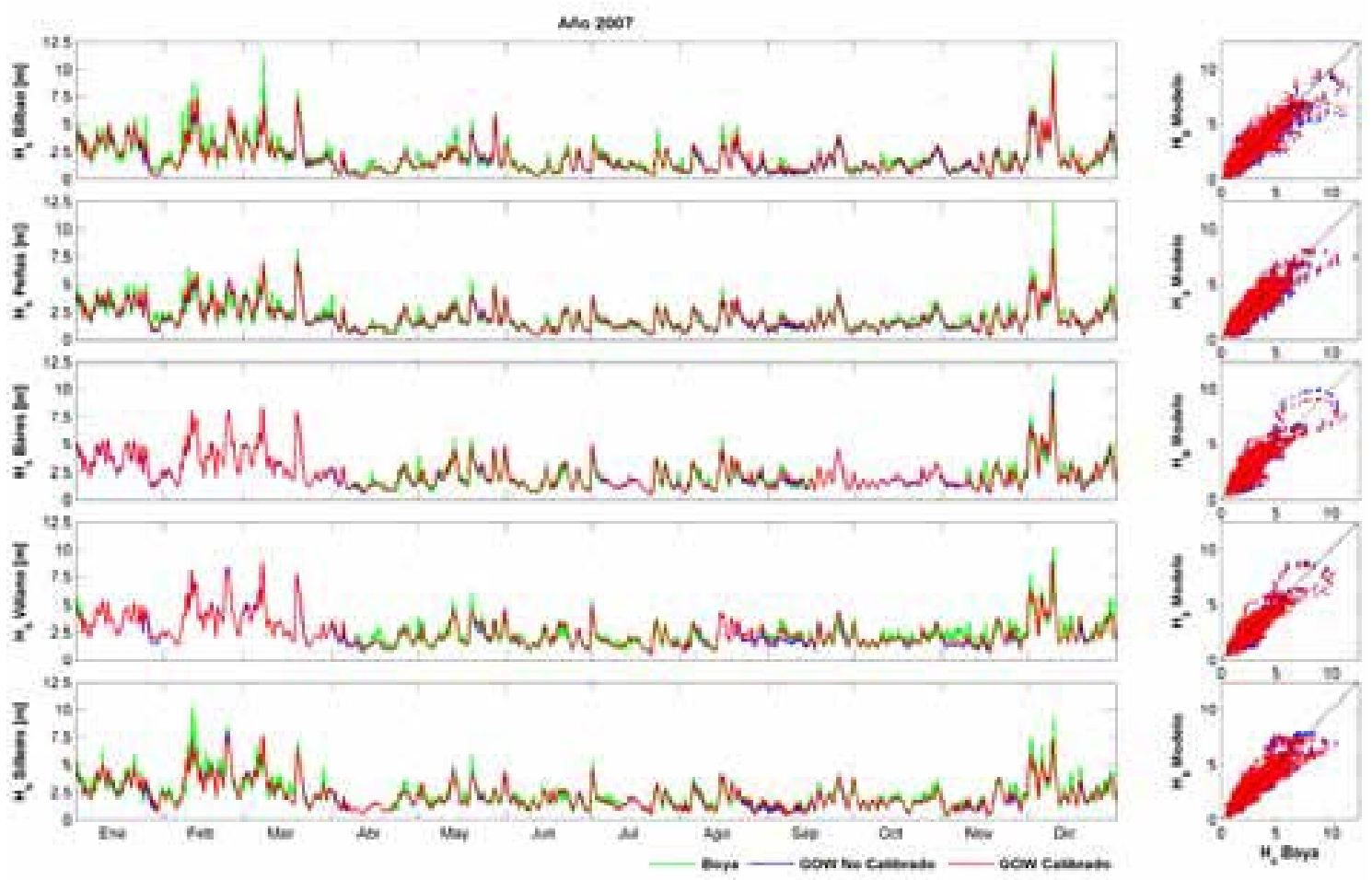

Figure 10. Validation of the calibration using the 5 deep water directional wave buoys of Northwest Spain. Only 2007 time series is shown. 


\section{XI $I^{\text {èmes }}$ Journées Nationales Génie Côtier - Génie Civil \\ Les Sables d'Olonne, 22-25 juin 2010}

\section{Data selection for propagation to the coast}

The goal of this phase of the general methodology for the propagation of the wave data bases to the coast is to select a set of sea states representing the deep water wave climate in a given propagation area. This selection is carried out using the algorithm of maximum dissimilitude (MaxDiss) that allows the identification of the subset of $M$ data with the biggest possible diversity in a data set of $\mathrm{N}$ data, CAMUS (submitted). This algorithm starts with the initialization of the subset $M$ with the selection of a data from the original set $\mathrm{N}$. Once the first data is selected, the following points of the subset $M$ are obtained looking for those data of the original set $\mathrm{N}$ that present the maximum dissimilitude with respect to the selected subset.

This process of sea state selection in deep waters is carried out for each one of the propagation meshes defined along the Spanish coast. The sea states to be selected are defined by the hourly series of spectral wave parameters and directional spectrum components corresponding to the nodes of the GOW data base located at the propagation mesh boundaries.

One of the main contributions of this methodology is that in the sea state selection process, the spatial variability in the boundary of the propagation domain is taken into account. This means that each hourly maritime climate is defined using the spatially varying wave conditions in the domain boundary and the spatially varying wind field inside the propagation domain. Figure 11 shows the wave propagation map for propagation domain G01 (East Cantabrian Sea) for the highest sea state of the selected set. In the figure, the spatial variation of wave height in the boundary of the propagation domain can be seen. The variation of wave height due to refraction in intermediate and shallow waters is also perceived.

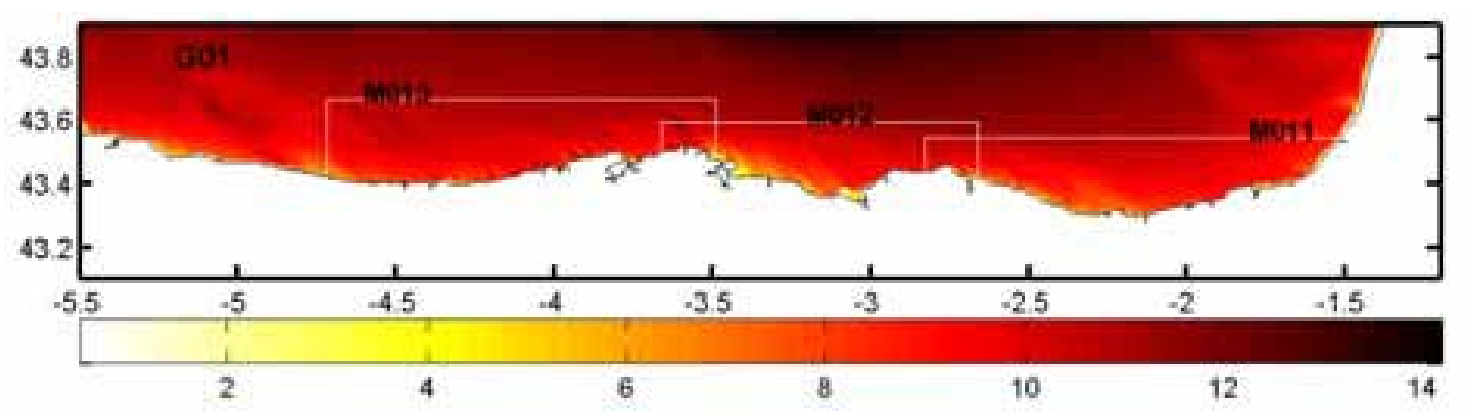

Figure 11. Wave propagation map in one selected sea and wind state in the propagation domain G01. Scale: Zero-moment wave height in $\mathrm{m}$.

The consideration of the spatial variability of waves and wind in the propagation domain causes the data base upon which the algorithm MaxDiss is applied to have very high dimensionality. Each sea state in one GOW node is composed of three spectral wave parameters, $H_{s}, T_{m}$ and $\theta_{m}$, and each wind state in each node of the atmospheric 
reanalysis adds two more parameters of the horizontal components of the wind, $\mathrm{W}_{\mathrm{x}}, \mathrm{W}_{\mathrm{y}}$. For example, figure 12 shows the reanalysis nodes taken into account in the propagation domain G01. As can be seen, there are 9 nodes of wave reanalysis in the domain boundary and 4 atmospheric nodes. The data vector for each sea state selected for propagation is therefore composed of 35 components:

$$
X_{i}=\left\{H_{s, 1}, T_{m, 1}, \theta_{m, 1}, \ldots, H_{s, 9}, T_{m, 9}, \theta_{m, 9}, W_{x, 1}, W_{y, 1}, \ldots, W_{x, 4}, W_{y, 4}\right\}_{i} \quad i=1, \ldots, N
$$

where in (1) $N$ is the total number of data in the original GOW1.0 data set, $N=534000$ and $n$ is the dimension of the data vector, in this case $n=35$.

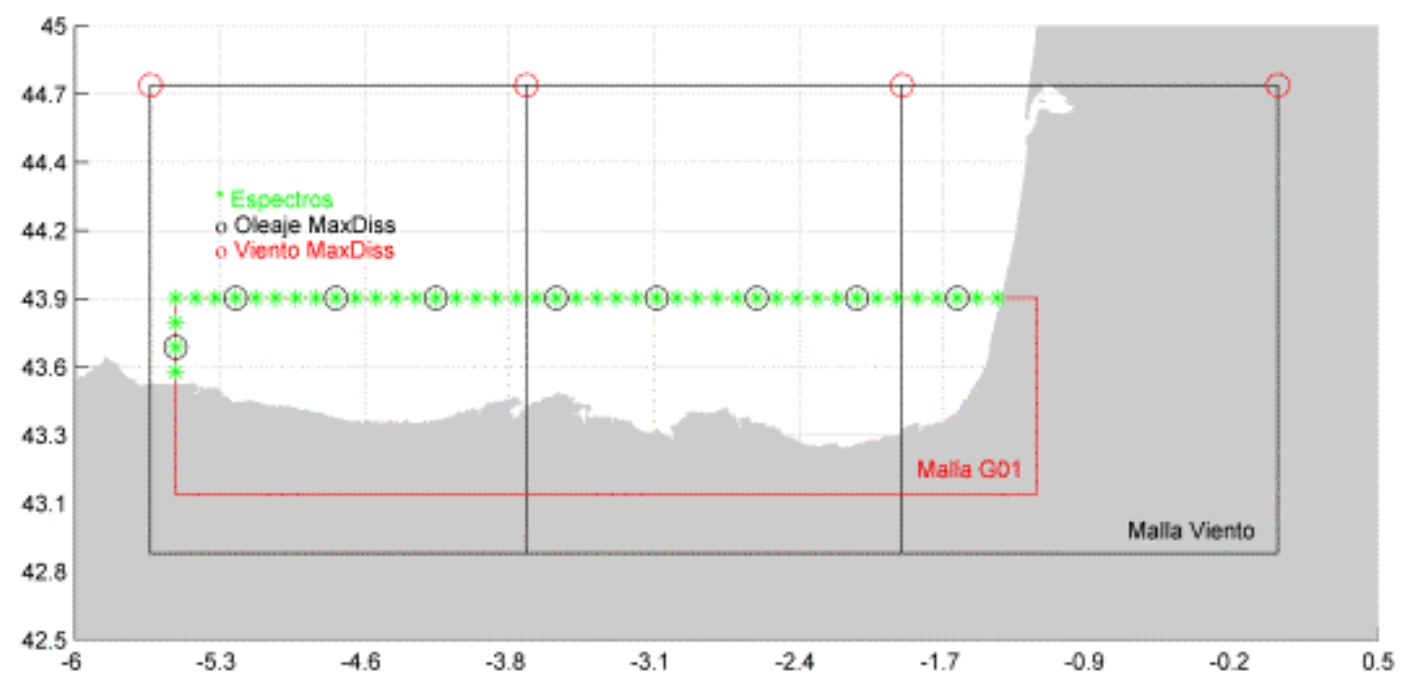

Figure 12. Wave wind data points used for the selection of a representative subset of data for wave propagation using the MaxDiss algorithm. Domain G01 (East Cantabrian Sea).

In general, the different components from the spaces with high dimensionality are correlated, meaning that the information is redundant. The Principal Component Analysis (PCA) technique allows reducing the dimensionality of a data set by projecting a new space with a smaller dimension while maintaining the maximum data variance. In the case of maritime climate in deep waters, the reduction of the dimensionality is simplified after the application of the MaxDiss selection technique.

The PCA technique splits a space-temporal numerical variable, $R(x, t)$ into a linear combination of modes or Empirical Ortogonal Functions (EOFs). The spatial modes define a new projection base and represent those spatial directions where the variance of data is the highest. The projections on this new base are the Principal Components (PCs). Therefore, the space-temporal numerical variable can be expressed as:

$R(x, t)=\overline{R(x)}+\sum_{i=1}^{n} E O F_{i}(x) \cdot P C_{i}(t)$ 
where in (2) $\overline{R(x)}$ is the variable's mean, $E O F_{i}(x)$ are the spatial modes or projection vectors, $P C_{i}(t)$ are the temporal components and $n$ is the spatial dimension of the original data. The data projection on each temporal mode explains a particular data variance. The EOFs are numbered from highest to lowest in terms of variance. As the objective is to project the data in a space of lower dimension, the numbers $d$ of EOFs considered should be $d<<n$.

$$
R(x, t) \square \overline{R(x)}+\sum_{i=1}^{d} E O F_{i}(x) \cdot P C_{i}(t)
$$

The use of this technique requires, first, the decomposition of the wave and wind directions in their zonal and meridional components $\left(\begin{array}{lll}x & \mathrm{e} & y\end{array}\right)$ and second, the standardization of all the data variables to avoid troubles due to scale differences. The decomposed data variables take the form:

$$
X_{i}^{\prime}=\left\{H_{s, 1}, T_{m, 1}, \theta_{m x, 1}, \theta_{m y, 1}, \ldots, H_{s, 9}, T_{m, 9}, \theta_{m x, 9}, \theta_{m y, 9}, W_{x, 1}, W_{y, 1}, \ldots, W_{x, 4}, W_{y, 4}\right\}_{i} \quad i=1, \ldots, N
$$

and after standardization:

$$
X_{i}^{*}=\left\{H_{1}, T_{1}, \theta_{x, 1}, \theta_{y, 1}, \ldots, H_{11}, T_{11}, \theta_{x, 1}, \theta_{y, 11}, W_{x, 1}, W_{y, 1}, \ldots, W_{x, 4}, W_{y, 4}\right\}_{i} \quad i=1, \ldots, N
$$

Applying the PCA to these data and taking into account that after standardization the temporal mean of each variable is zero, each data variable is defined by:

$$
X^{*}(x, t)=\sum_{i=1}^{d} E O F_{X^{*} i}(x) \cdot P C_{X^{* i}}(t)
$$

Once the multidimensional data set of sea state variables is defined and their multidimensionality reduced by their projection on the base formed by the EOFs, the MaxDiss algorithm is applied to the PCs, $P C_{X^{\prime} i}(t)$ of the reduced space to select the subset of $M$ cases (sea and wind states) representing the original data base. These M sea states are then propagated using a numerical model of wave propagation. For the Atlas, a number of $d=13$ PCs that explains the $99.0 \%$ of the total variance of the original data have been considered.

The first selected sea state corresponds to the one which has the highest zero-moment wave height in the domain boundary. The subset of sea states selected using the MaxDiss algorithm in the EOFs projection space is not rebuilt by means of the $d$ spatial modes $E O F_{X^{i} i}$ considered to return to the original space. Instead, the selected cases are searched in the original data base, so the propagated sea states are real ones.

The subset made up by the $M=500$ cases in the EOFs projection space is defined as:

$D_{j}^{E O F}=\left\{P C_{x^{* 1}}^{D}, \ldots, P C_{X^{*} d}^{D}\right\}_{j} \quad j=1, \ldots, M$

and the original data space is defined by

$D_{j}=\left\{H_{s, 1}^{D}, T_{m, 1}^{D}, \theta_{m, 1}^{D}, \ldots, H_{s, 1}^{D}, T_{m, 1}^{D}, \theta_{m, 1}^{D}, W_{x, 1}^{D}, W_{y, 1}^{D}, \ldots, W_{x, 1}^{D}, W_{y, 19}^{D}\right\}_{j} \quad j=1, \ldots, M$

Figure 13 shows an example of the distribution of the selected sea states (in green) and the original data (in red) for three spectral wave parameters $\left\{H_{s}, T_{m}, \theta_{m}\right\}$ and the two wind parameters $\left\{W_{x}, W_{y}\right\}$. 

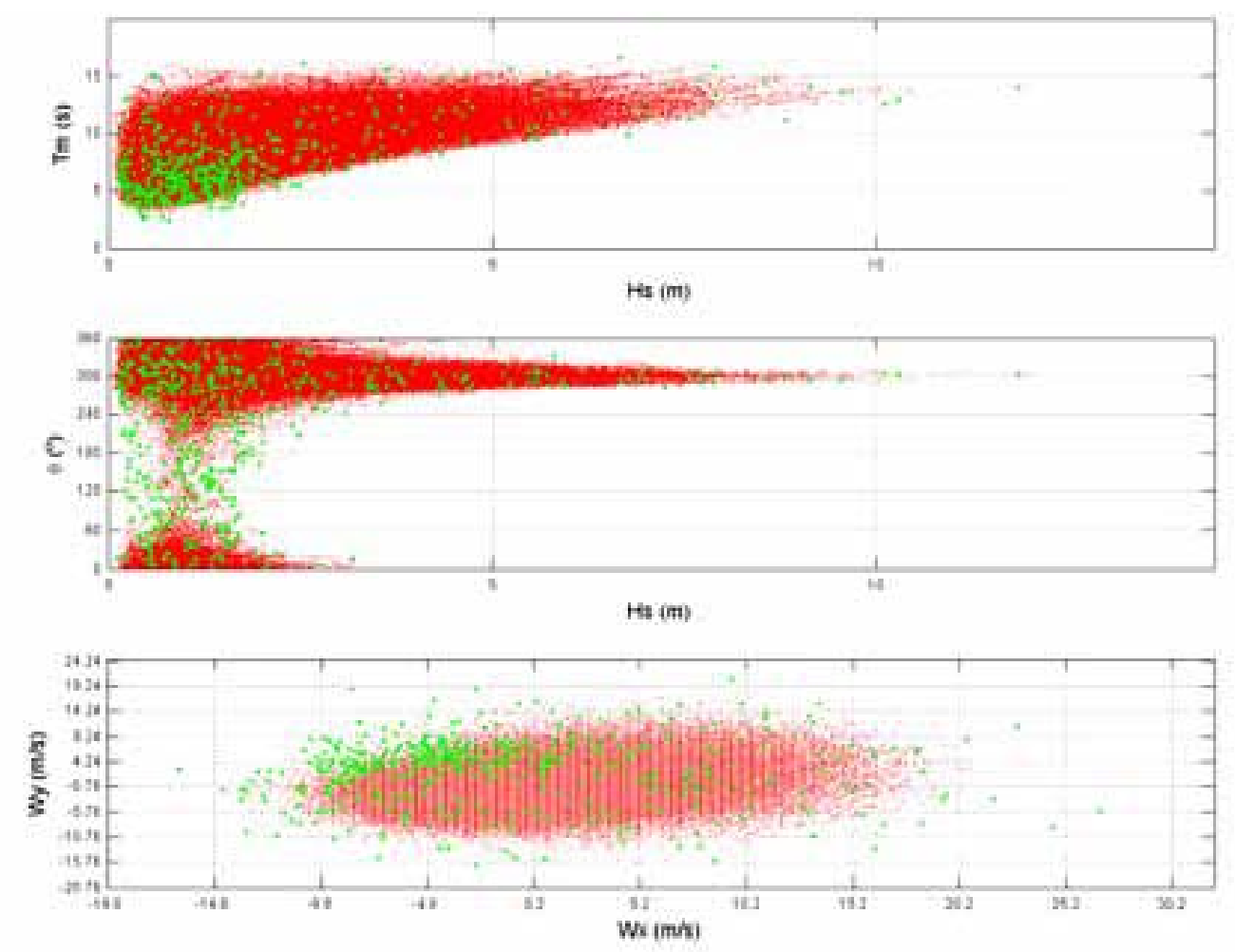

Figure 13. Example of distribution of the selected sea states corresponding to three wave parameters and the two wind parameters using the MaxDiss algorithm.

The scheme of figure 14 summarizes the technique developed for selecting the representative sea states in a given propagation domain taking into account the spatial variability of the original data in the deep water boundary of the domain.

\section{Wave propagation to the coast}

Given the high demand of spatial resolution along the coast requested for the Atlas (( $200 \mathrm{~m})$, the spectral wave propagation model SWAN, developed by Delft University of Technology has been selected. This model is based on the wave action equation that averages the phase and does not build the free surface in the space-time domain, BOOIJ et al. (1999). The last versions of this model have incorporated phenomena characteristic of shallow water wave propagation, such as wave breaking and non-linear interactions (triads) that have allowed an increase in the range of application of this model. Being one energy model, the wind generation inside de propagation domain can be taken into account. 

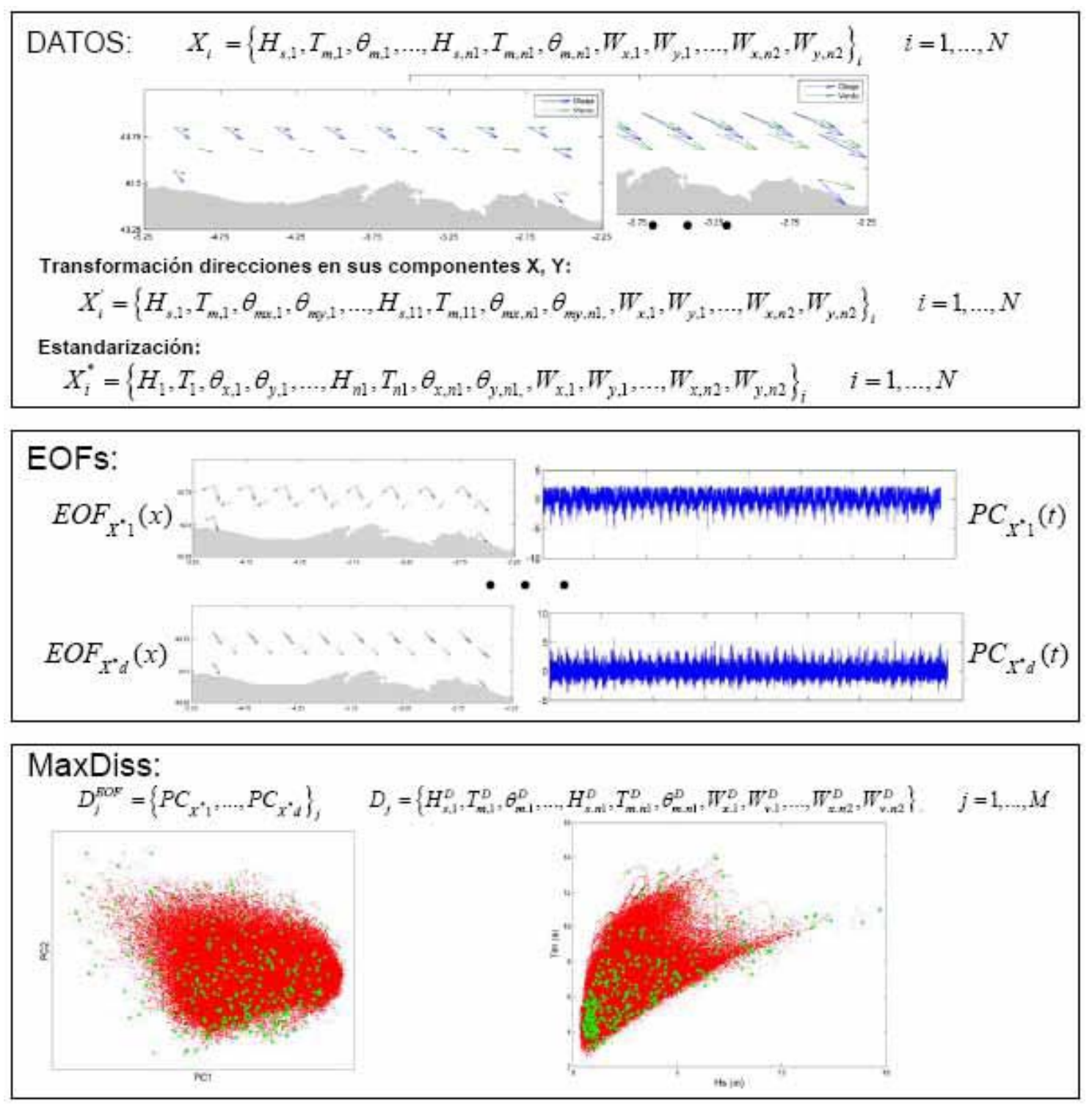

Figure 14. Scheme of the technique developed for selecting the representative sea states in a given propagation domain taking into account the spatial variability of the original data in the deep water boundary of the domain.

The $M=500$ selected sea states, that represent the original data base of waves in the deep water boundary of the domain and the original wind data base inside the domain, are propagated to the coast using the SWAN model. The propagation results are the spectral wave parameters in the nodes of the corresponding computation mesh of the propagation domain. For the Atlas, the following spectral sea-state parameters have been obtained: zero-moment wave height $\left(\mathrm{H}_{\mathrm{m} 0}\right)$ mean period $\left(\mathrm{T}_{\mathrm{m}}\right)$ peak period $\left(\mathrm{T}_{\mathrm{p}}\right)$ mean wave direction $\left(\theta_{\mathrm{m}}\right)$ mean wave power $\left(\mathrm{P}_{\mathrm{w}}\right)$ and the mean direction of the mean wave power $\left(\theta_{\mathrm{p}}\right)$. 
Figure 15 shows the propagation results for the zero-moment wave height and mean wave direction for case 1 selected using MaxDiss in the propagation domain G01 (East Cantabrian Sea).

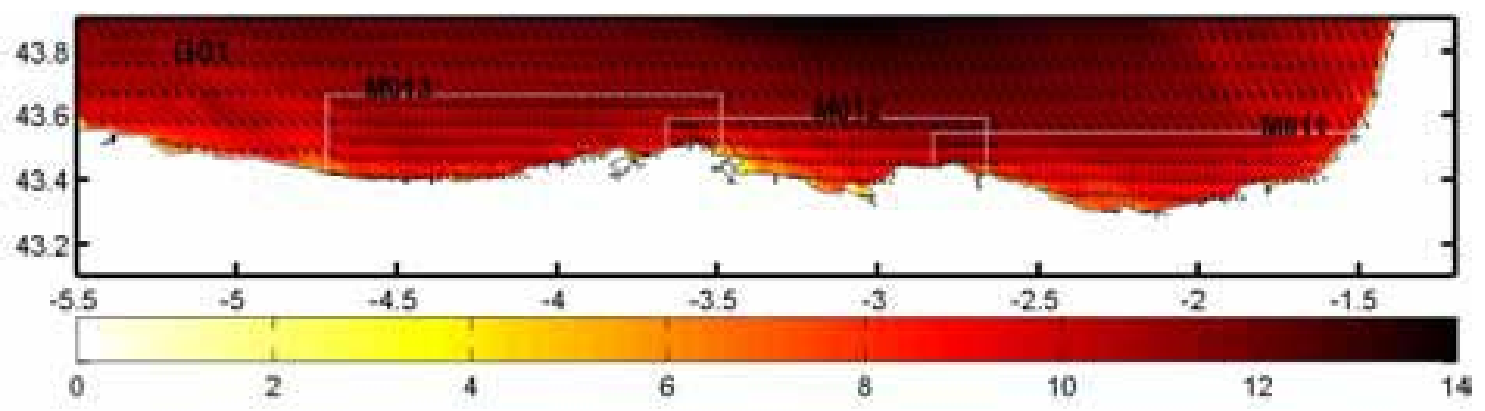

Figure 15. Propagation results for the zero-moment wave height and mean wave direction for the case 1 selected using MaxDiss in the propagation domain G01 (East Cantabrian Sea).

The set of the $M=500$ wave propagations carried out in all the propagation domains established for the Spanish coast define a library of cases. This library is composed by the 500 hourly values of the spectral parameters considered $\left\{H_{m 0}, T_{m}, T_{p}, \theta_{m}, P_{w}, \theta_{p}\right\}$ in the nodes of the computation domain (domains G, M and GM) corresponding to a given climatic conditions in deep water. Figure 15 shows a scheme of the characteristics of this library in the domain G01. In this case, only the spectral parameter $H_{m 0}$ has been represented, as it is similar to that of the other parameters.

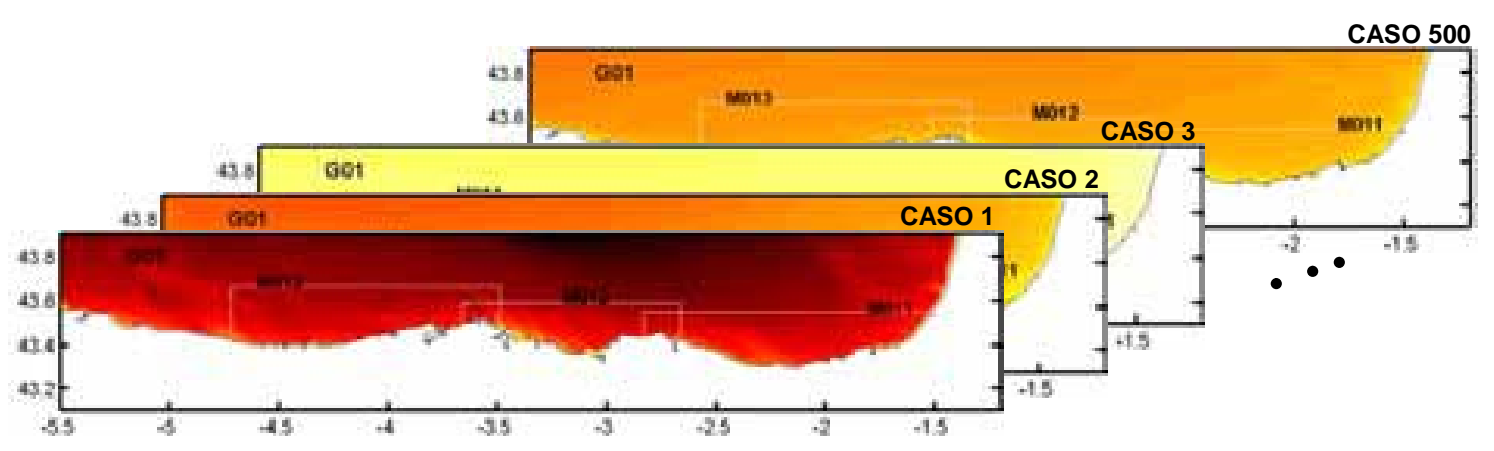

Figure 16. Scheme of library of cases generated from the 500 selected cases.

Every one of the $M=500$ propagated cases represents a set of wave data in deep waters, namely, those maritime weather situations with similar wave and wind conditions on the boundary of the propagation domain. This set of generated data is called Downscaled Ocean Waves (DOW). The number of wave conditions in deep waters represented in each case can be expressed as a probability equal to the number of represented cases divided by the total number of sea states in the original data base. This probability 


\section{XI $I^{\text {èes }}$ Journées Nationales Génie Côtier - Génie Civil \\ Les Sables d'Olonne, 22-25 juin 2010}

allows the spatial representation of the wave power in different time scales in a very simple way, as will be explained in the next paragraph.

\subsection{Time series reconstruction in the propagation domain}

The time series reconstruction in the nodes of the computation mesh of the propagation domain is carried out through a multidimensional interpolation on the subset of the $M=500$ propagated cases. The interpolation technique used is the Radial Basis Functions (RBF) that is particularly efficient for data of very high dimensionality and with nonuniform distribution, FRANKE (1982). For the Atlas, Gaussian radial functions have been used. These functions have a form parameter whose optimal value can be obtained using the algorithm proposed by RIPPA (1999).

To implement the RBF technique for the reconstruction of the hourly time series of spectral wave parameters on the propagation domain, we make use of the $M \mathrm{~d}$ dimensional points:

$$
D_{j}^{E O F}=\left\{P C_{x^{*} 1}^{D}, \ldots, P C_{x^{*} d}^{D}\right\}_{j} ; j=1, \ldots, M
$$

The data correspond with the MaxDiss selected sea state cases in the deep water boundary of the propagation domain, where $d$ is equal to the number of PCs considered in the projection of the original data based on the EOFs (base). The exact value of the Gaussian RBF in these points, $f_{j}(x)$ is equal to the spectral parameters obtained as a result of the propagation to the target point: the propagated zero-moment wave height $\left\{H_{m 0 p, j}^{D}\right\}$, the peak period $\left\{T_{p p, j}^{D}\right\}$, the $x$ and $y$ components of the propagated mean direction $\left\{\theta x_{m p, j}^{D} \theta y_{m p, j}^{D}\right\}$, the propagated mean power $\left\{P_{w p, j}^{D}\right\}$ and the components of the propagated mean direction of the mean power $\left\{\theta x_{p p, j}^{D} \theta y_{p p, j}^{D}\right\}$. The objective of this interpolation technique is to calculate an interpolation function for: 1) the propagated zero-moment wave height $\left.H_{m 0 p}, R B F_{H}, 2\right)$ the propagated peak period $\left.T_{p p}, R B F_{T}, 3\right)$ the $\mathrm{x}$-component of the propagated mean direction $\left.\theta x_{m p}, R B F_{\theta x}, 4\right)$ the $\mathrm{y}$-component of the propagated mean direction $\left.\theta y_{m p}, R B F_{\theta y}, 5\right)$ the propagated mean power $P_{w p}, R B F_{P_{w}}$ and 6) the $\mathrm{x}$ - and $\mathrm{y}$ - components of the propagated mean direction of the mean power $\theta x_{p p}, \theta y_{p p}, R B F_{\theta x_{p}}$. These RBF functions allow deriving the values of propagated wave spectral parameters in any point of the propagation domain, namely, any sea state in deep water projected in the EOFs space $X_{i}^{E O F}=\left\{P C_{X^{*} 1}, \ldots, P C_{X^{*} d}\right\}_{i} ; i=1, \ldots, N$ can be transferred to any point of the propagation domain, obtaining in these points the reanalysis time series given by:

$$
X_{p, i}=\left\{H_{s p, i}, T_{m p, i}, \theta_{m p, i}\right\}(i=1, \ldots, N)
$$

If there is a significant astronomical tide in the propagation domain the MaxDiss selected cases should be propagated with $\mathrm{Q}$ different sea levels $\left(z_{q} ; q=1, \ldots, Q\right)$. For the Atlantic propagation domains, three sea levels were chosen for propagation Maximum Spring Low Tide (MSLT) $\mathrm{z}_{1}=0.0 \mathrm{~m}$, Mean Sea Level (MSL) $\mathrm{z}_{2}=2.5 \mathrm{~m}$ and Maximum 
Spring Hight Tide (MSHT) $\mathrm{z}_{3}=5.0 \mathrm{~m}$. In the Mediterranean propagation domains, only the $(\mathrm{MSLT}) \mathrm{z}_{1}=0.0 \mathrm{~m}$ has been considered.

\subsection{Propagated time series validation}

The technique presented above for the reconstruction of the GOW reanalysis time series in the nodes of the computation mesh of the propagation domain has been validated comparing the results with the corresponding time series of the available wave buoys located around the Spanish coasts. The sea state wave parameters used in the validation are the zero-moment wave height, $\left(H_{m 0}\right)$, the peak period $\left(T_{p}\right)$, the mean direction $\left(\theta_{m}\right)$, the mean power $\left(P_{w}\right)$ and the mean direction of the mean power $\left(\theta_{p}\right)$.

As an example, figure 17 shows the comparison between the reconstructed GOW time series in the position of Bilbao coastal wave buoy (red) and the time series measured by the buoy (blue). The upper plots are the scatter diagrams for the three wave parameters $\left(H_{m 0}, T_{p}, P_{w}\right)$. The plots in the middle are the time series of mean power and the mean yearly power and the mean direction of the mean power and the mean yearly power direction (the buoy has been operating in this position from 1985 to 2005). Finally, the plots below represent the mean monthly power and the rise of mean power direction. As can be seen in the figure, the methodology presented is able to reproduce the temporal structure of the wave climate in the coast.

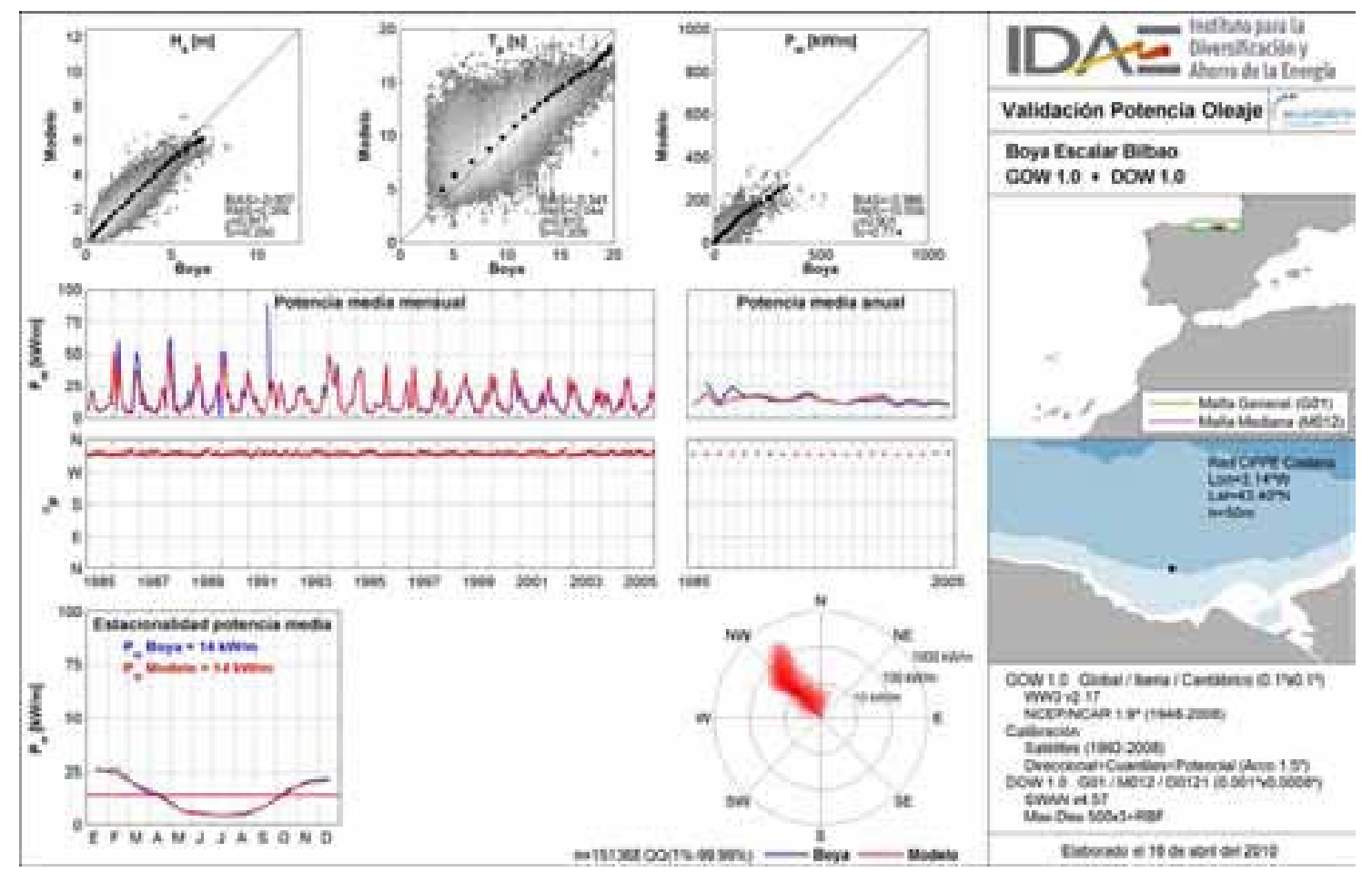

Figure 17. Validation sheet of the methodology presented corresponding to Bilbao coastal wave buoy. 


\section{XI $I^{\text {èmes }}$ Journées Nationales Génie Côtier - Génie Civil}

Les Sables d'Olonne, 22-25 juin 2010

\subsection{Methodology for the statistical analysis of the wave energy resource}

The mean energy flux or the mean power is the sea state parameter commonly used to express the power of the waves. If a sea state is represented by its directional spectrum $S(\omega, \theta)$, the mean power is computed taking the time average of the energy flux crossing a cylinder of unit length diameter and extended from the free surface to the seabed. The time average of the energy flux (power/unit length) of a wave component of frequency $\omega_{i}$, direction $\theta_{i}$ and energy/unit area $\rho g S_{i}$ travelling on a water depth $h$ is given by the product of $\mathrm{S}_{\mathrm{i}}\left(\omega_{i}, \theta_{i}\right)$ by the energy or group velocity, $\mathrm{C}_{\mathrm{gi}}\left(\left(\omega_{I}, h\right)\right.$. Adding the energy of all the frequency-direction components, the mean power is expressed as:

$$
P_{w}=\rho g \int_{0}^{2 \pi} \int_{0}^{\infty} c_{g}(\omega, h) S(\omega, \theta) d \omega d \theta
$$

where $\rho$ is the water density and $g$ is the gravity acceleration. The mean direction of the mean power is given by:

$$
\theta_{p}=\arctan \frac{\int_{0}^{2 \pi} \int_{0}^{\infty} c_{g}(\omega, h) S(\omega, \theta) \sin (\theta) d \omega d \theta}{\int_{0}^{2 \pi} \int_{0}^{\infty} c_{g}(\omega, h) S(\omega, \theta) \cos (\theta) d \omega d \theta}
$$

The sea states in the most commonly used reanalysis data bases are defined by the spectral parameters $\left(H_{m 0}, T_{m}, T_{p}, \theta_{m}\right.$, etc.) and in some cases they are decomposed into SEA and SWELL components. To propagate these data bases to the coast, some theoretical spectral function $S(\omega, \theta)$, must be chosen to describe each propagated sea state. The advantage of the GOW data base is that it uses the spectral components obtained from the wave reanalysis for the propagation, so no hypothesis about the spectral shape in the propagation domain boundary must be made.

The propagation of the $M=500$ sea states selected using the MaxDiss algorithm provides the sea state parameters $\left(H_{m 0}, T_{m}, T_{p}, \theta_{m}, P_{w}, \theta_{p}\right)$ in all the nodes of the computation mesh of the propagation domain (typical resolution $\approx 200 \mathrm{~m}$ ) and in all the domains defined around the Spanish coast. Using the RBF interpolation technique, the library of propagated sea states can be used to reconstruct the complete time series of wave parameters, having the same time span and temporal resolution as the original GOW data base.

As every one of the 500 selected sea states is associated to a number of sea states on the original data base, a probability of presentation can be assigned to every one of these 500 sea states. This probability can be used to compute a fast approximation of the mean power from the 500 cases without reconstructing the complete data base through the RBF interpolation. Both methods have been used in the Atlas. Figure 18 shows the comparison between the cumulated probability distribution functions (cdf) of the mean power in a point near the coast calculated using both methods. As can be seen in the figure, the simplified method (using the 500 cases and the probability of presentation) gives a rougher representation, but still gives an accurate enough cdf, compared to the cdf calculated with the 534000 sea states of the complete reconstructed data base. 


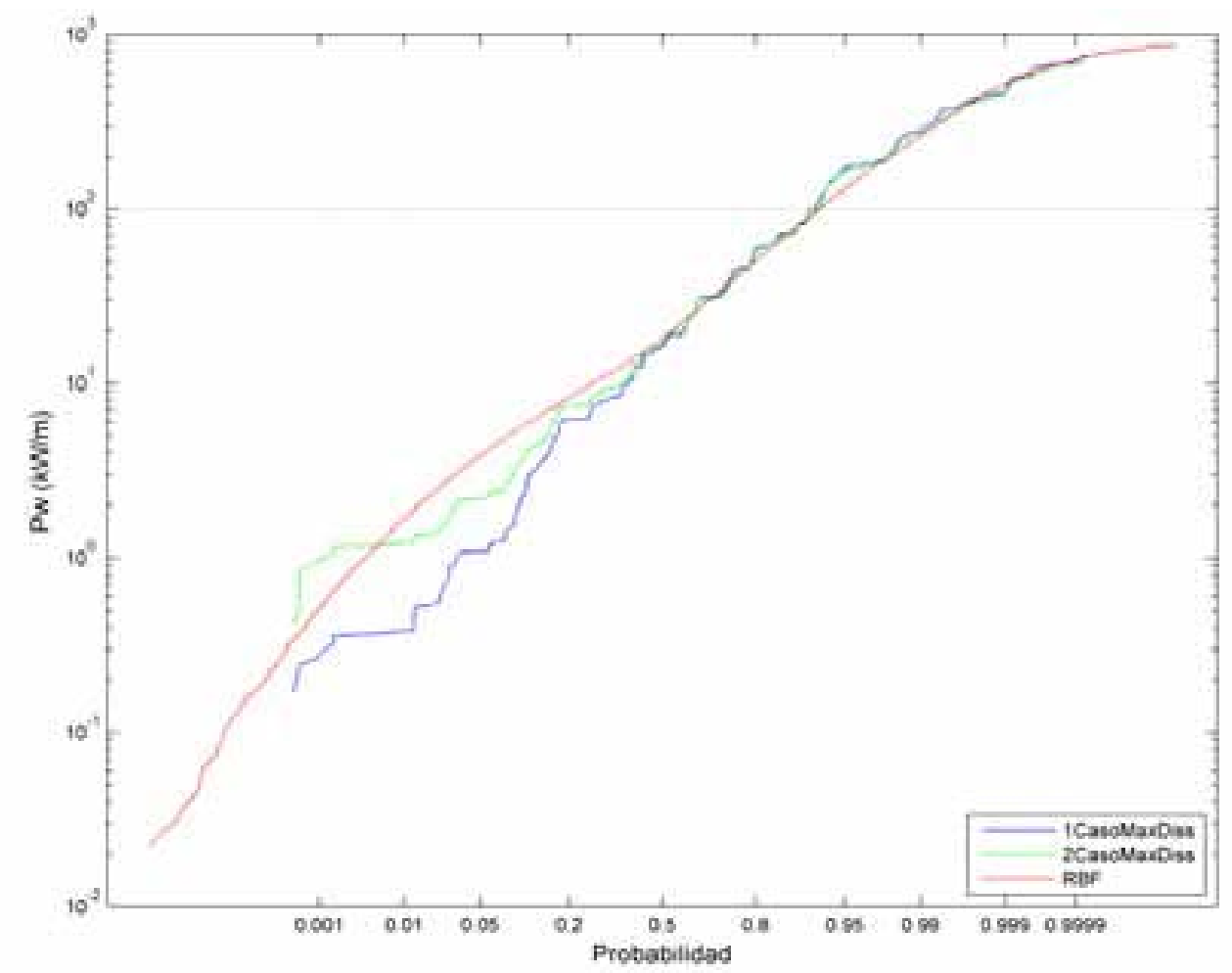

Figure 18. Comparison of cdfs of mean power in one propagation point calculated using the 500 selected sea states and their probability of presentation (green line) and the 534000 sea states of the fully reconstructed data base through the RBF interpolation (red line).

\section{Spanish Atlas of wave energy resource}

The methodology presented in the previous paragraphs has been used to create the Spanish Atlas of wave energy resource around the coast. In this paragraph, some of the Atlas figures are presented. The maps presented in the Atlas characterize the yearly mean power, the $95 \%$ power quantile and the seasonality of the mean power.

The maps showing the mean wave power distribution along the Spanish coast are presented in GIS format. As an example of these maps, figure 19 shows the map corresponding to the mean yearly wave power and the yearly mean direction of the wave power in the domain G03 of the Atlantic (Northwest of Galicia). Note in the figure that wave climate in this Atlantic area is fairly uniform, with a mild decrease of the mean yearly power to the South and to the East. Only near the coast, the influence of the water depth on the wave propagation modifies the spatial distribution of the mean power. Similar results are shown in figure 20, where the $95 \%$ quantile of the mean power is presented. In this case the much higher power values highlight the spatial differences in the wave power. 


\section{XI $I^{\text {èmes }}$ Journées Nationales Génie Côtier - Génie Civil}

Les Sables d'Olonne, 22-25 juin 2010

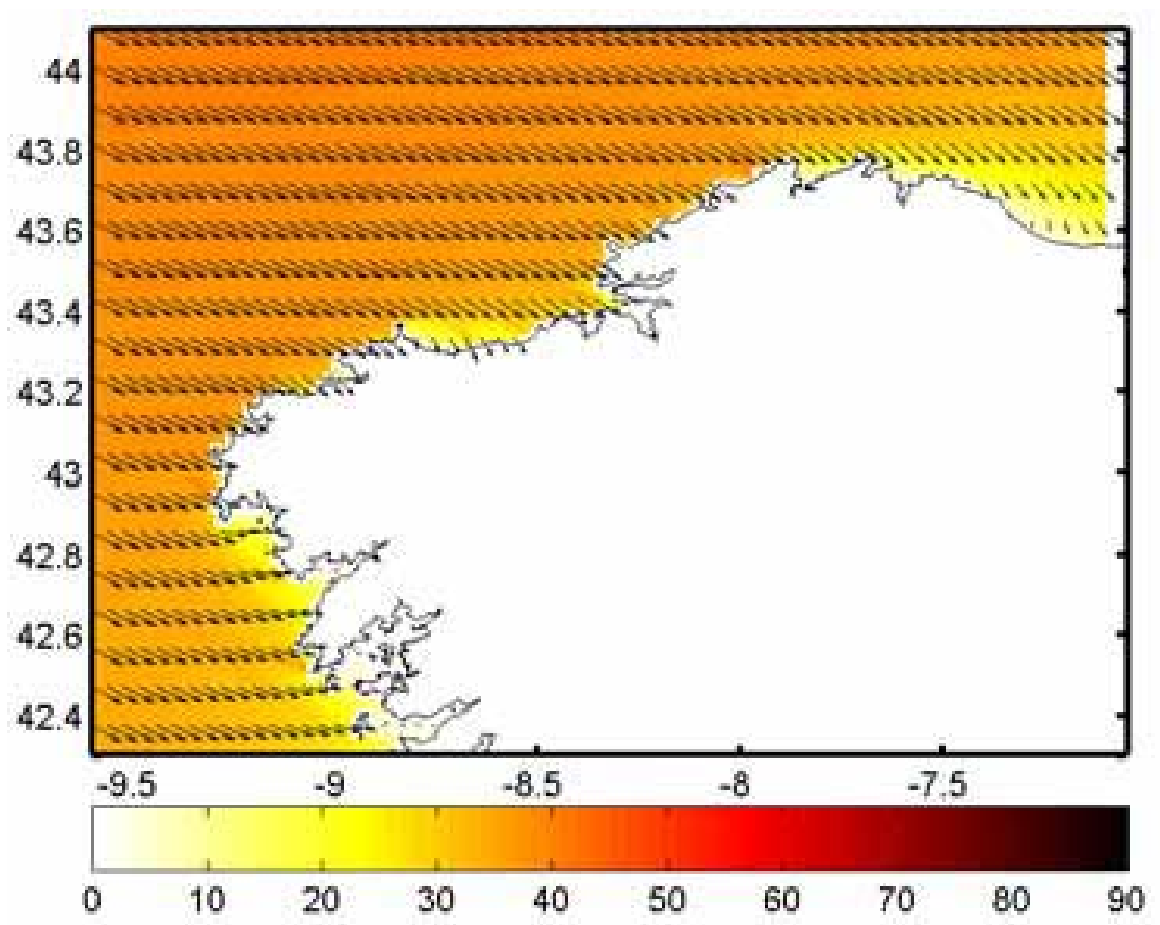

Figure 19. Mean yearly power in propagation domain G03 (Northwest Atlantic).

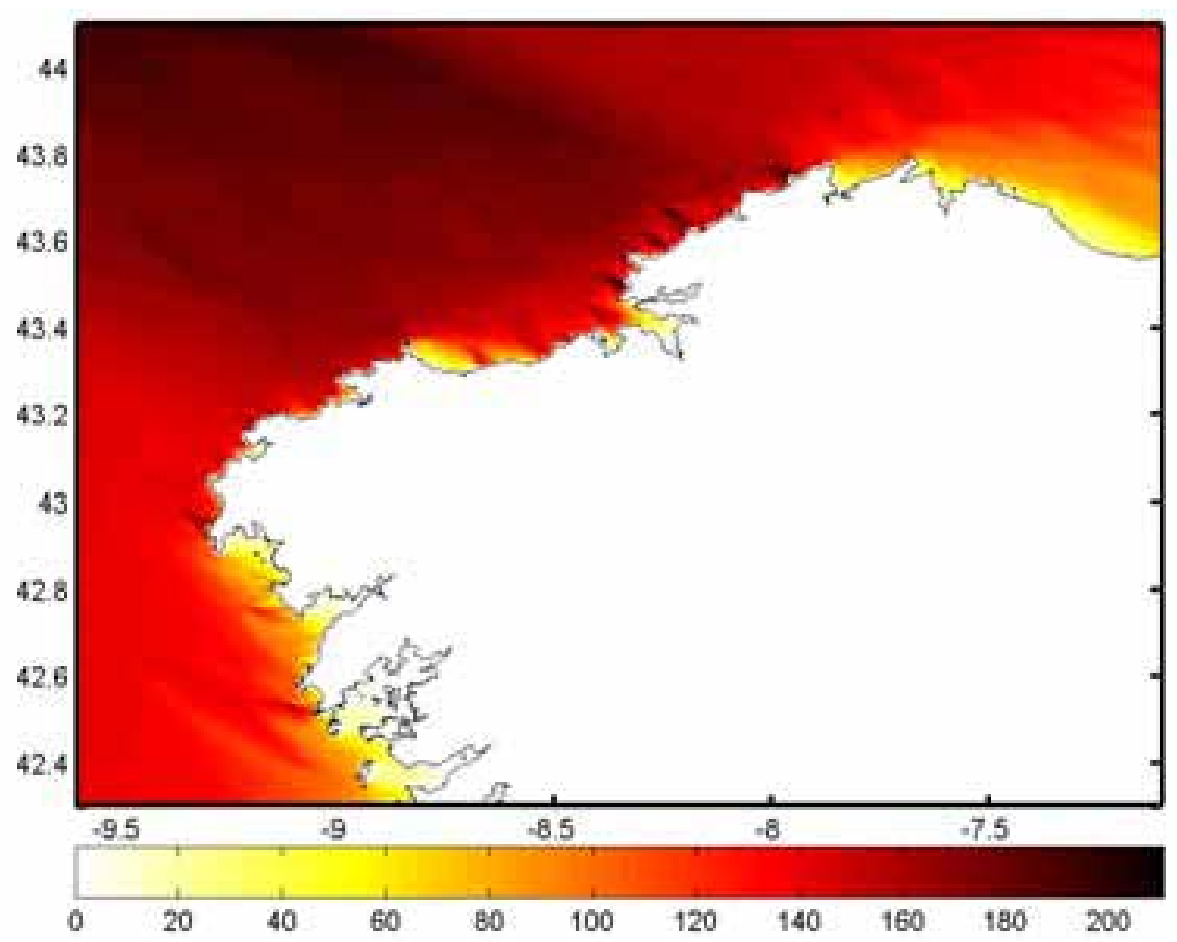

Figure 20. Illustration of the 95\% quantile of the wave power in domain G03 (Northwest Atlantic). 
Figure 21 shows the seasonal distribution of the mean wave power in domain G03 with four maps corresponding to winter (DEF) spring (MAM) summer (JJA) and fall (SON). The strong differences between the different seasons are clearly represented, especially those existing between winter and summer. Spring and fall have similar wave power.
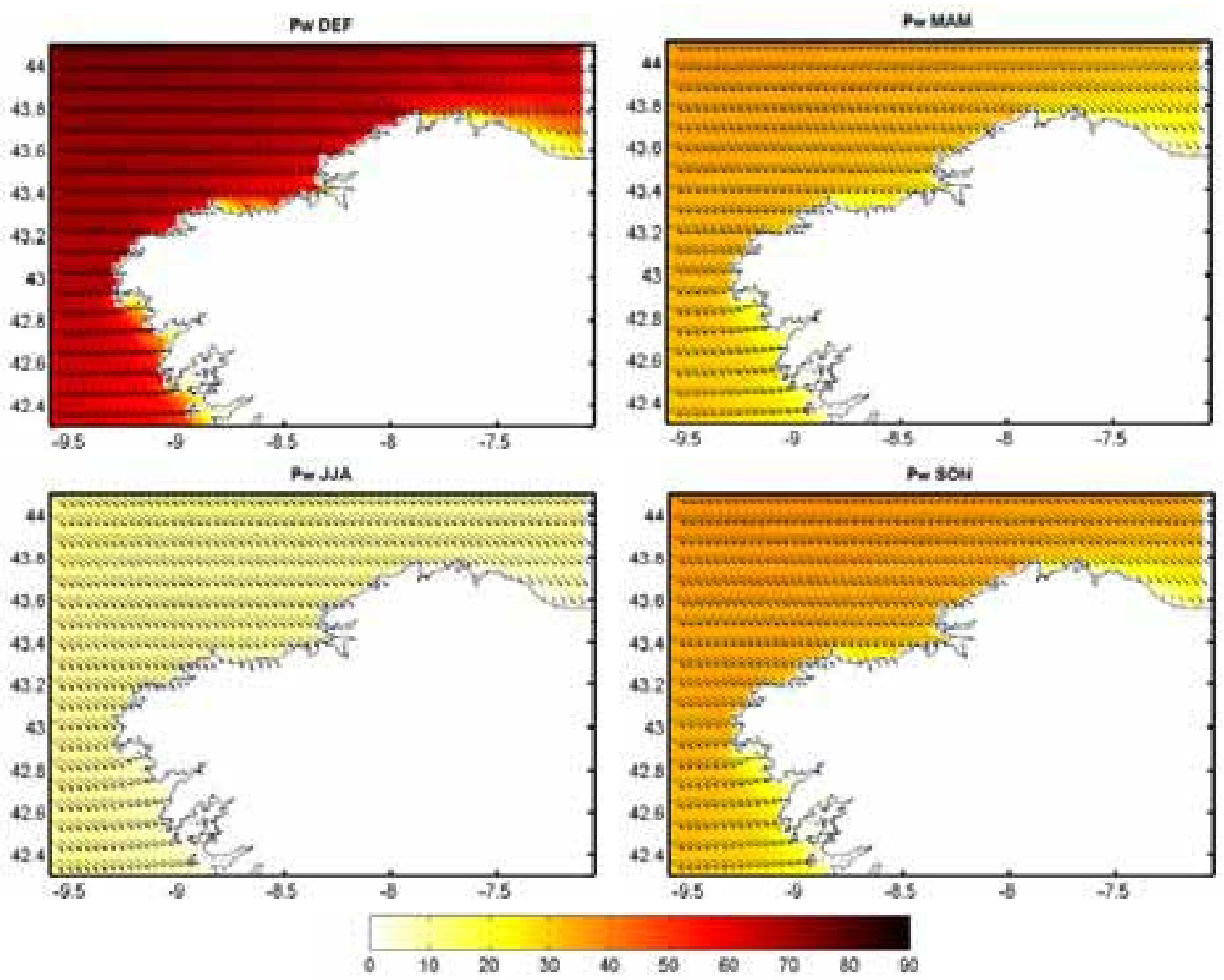

Figure 21. Seasonality of the mean wave power in domain G03 (Northwest Atlantic). Winter (DEF) Spring (MAM) Summer (JJA) Fall (SON).

Figure 22 shows the mean direction of the mean wave power and energy percentage corresponding to each $22.5^{\circ}$ directional sector for January and July in propagation domain G03 (Northwest Atlantic). As can be seen in the figure, the wave energy in January has a bigger western component than in July, reflecting the influence of the trajectory of the North Atlantic storms, which in winter move towards the South, while in summer, the Azores high displaces northwards the much milder storms allowing Northerly winds being more frequent. This meteorological behaviour is reflected in the directional distribution of the mean wave power: in January, the higher percentages of energy come from the directions W-WNW-NW, while in July the more energetic directions are NW-NNW. 

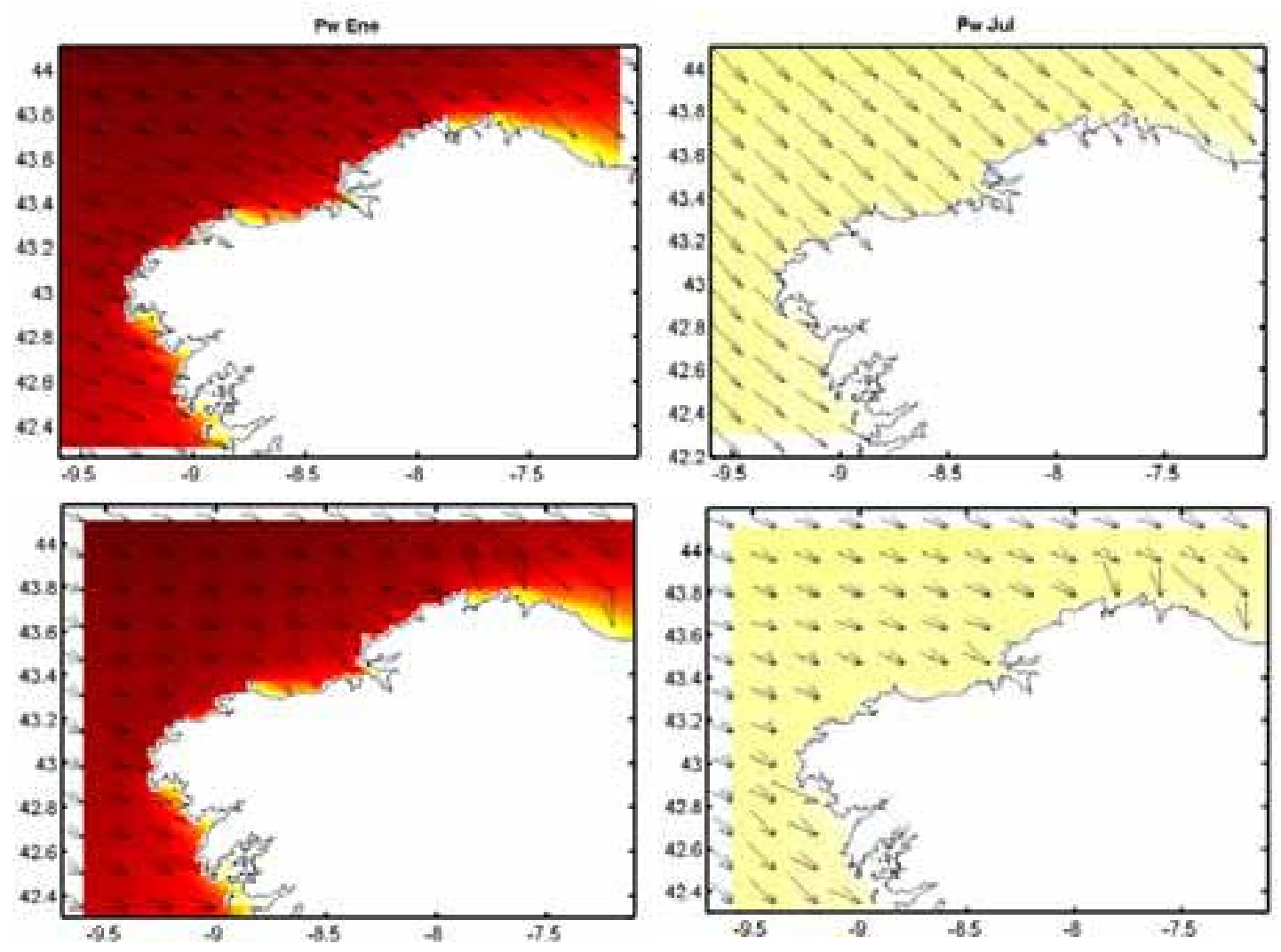

Figure 22. Mean direction of the mean wave power (above) and energy percentage corresponding to each $22.5^{\circ}$ directional sector for January (left) and July (right) in propagation domain G03 (Northwest Atlantic).

The characterization of the wave energy resource along the Spanish coast is presented in the Atlas with a spatial resolution of $0.1^{\circ} \times 0.1^{\circ}$ at three water depth contours: 20,50 and $100 \mathrm{~m}$ and in deep water. This information has been plotted in a map for each point of interest as shown in figure 23. In these maps, the following figures are presented:

1) The mean power and the directional distribution of the mean power for the year and for the four seasons is presented.

2) The monthly distribution of the quantiles 1, 5, 20, 50, 80, 95 and $99 \%$ of the mean wave power.

3) The cdf distribution of the mean wave power, for the year and for the four seasons.

4) Propagation domains used.

5) Coordinates of the selected point. 


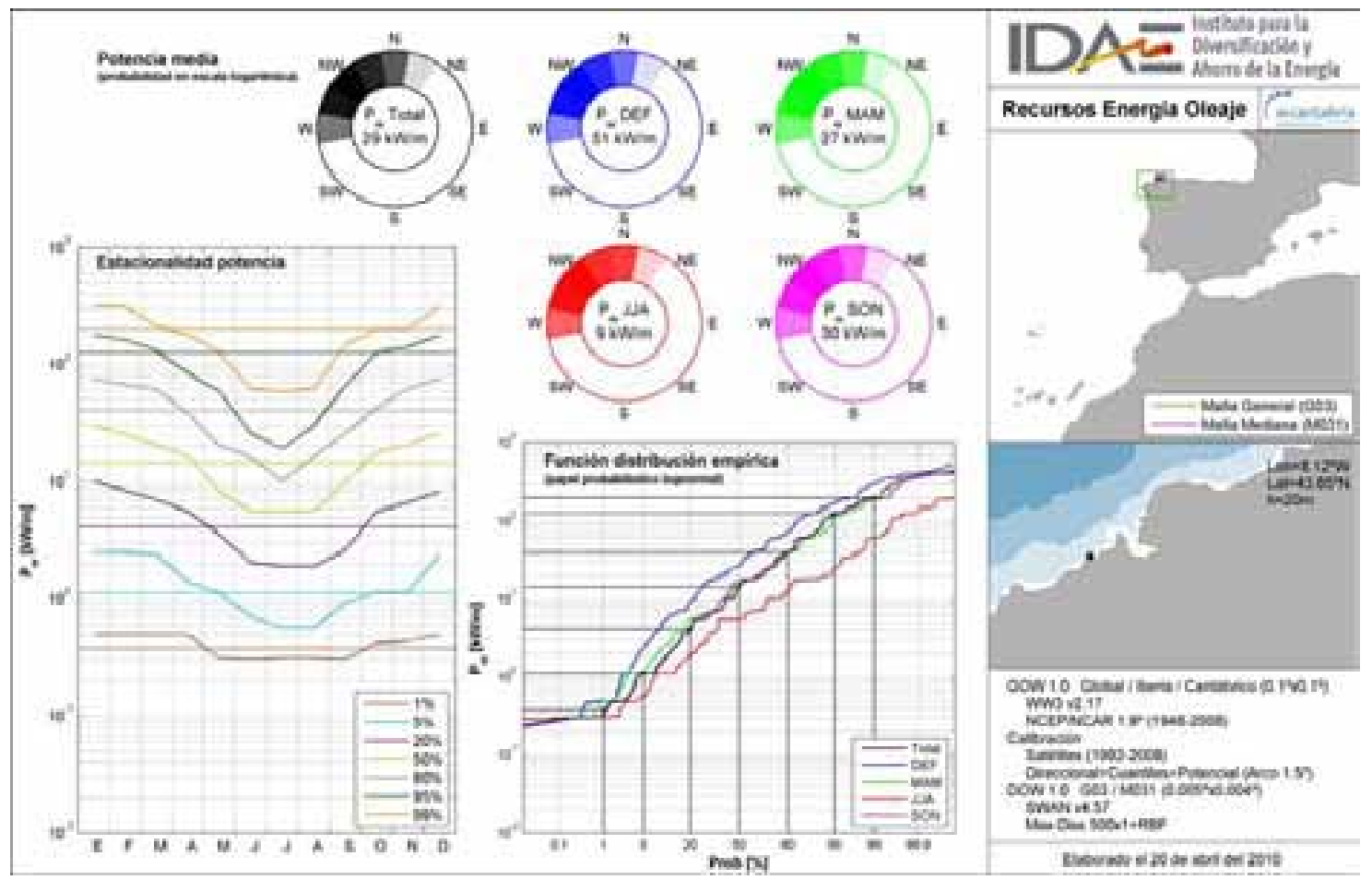

Figure 23. Energy map with the wave power statistical characterization at different time scales (yearly, seasonal, and monthly).

\section{Conclusions.}

The data bases created by atmospheric reanalysis, wave propagation models and the existence of a broad data base of instrumental wave data has allowed a great qualitative jump in the studies of the wave energy resource along the coasts. For this purpose IH Cantabria has developed a methodology to characterize the wave energy resource on the coast. The main advances of this methodology have been:

- Regeneration of a global reanalysis atmospheric data base and two regional wave data bases with high spatial and temporal resolution. For each sea state of these data bases, spectral wave parameters have been stored as well as the components of the directional wave spectrum in the propagation domain boundary.

- A procedure that selects a subset of sea states that represent the full data base of sea state conditions on the propagation domain boundary has been developed. As the spatial variation of sea state parameters on the domain boundary are taken into account, the high dimensionality of the data is reduced using the Principal Component Analysis. After the PCA projection, the sea states to be propagated are selected using the MaxDiss algorithm. 
- The latest version of the SWAN spectral wave propagation model is used to propagate the directional spectral components of all the selected sea states through the propagation domain, with a typical resolution of around $200 \mathrm{~m}$. This model takes into account wind generation on the propagation domain, wave breaking and nonlinear interaction between components

- The full data base is reconstructed in each computation point of the propagation domain using the RBF interpolation technique.

Using the developed methodology, IH Cantabria has produced the Spanish Atlas of Wave Energy Resource, with statistical information about the wave power along the Spanish coast in different time scales.

Despite the great advances made there is still much space for improvements in all the steps of the methodology: calibration of atmospheric and wave data bases, selection of propagation cases with their full dimensionality (separating the spectral components), assignation of probability to each of the selected propagation cases, propagation models, etc. On the other hand, the instrumental information from wave buoys is still scarce and their improvement and maintenance depend on state, regional or private organisms that should commit to continuing this task, as they are fundamental for the calibration and validation of data bases employed in the analysis of many ocean resources.

\section{Aknowledgements}

The methodology presented in this paper has been developed by the IH Cantabria under the project "Evaluación del potencial de energía de las olas en España para la elaboración del Plan de Energías Renovables 2011-2020" from the Instituto para la Diversificación y Ahorro de la Energía (IDAE) of the Spanih Ministerio de Industria, Turismo y Comercio.

\section{References.}

BOOIJ N., RIS R.C., HOLTHUIJSEN L.H. (1999). A third-generation wave model for coastal regions. Part I: model description and validation. Journal of Geophysical Research, 104 (C4), pp 7649-7666. doi:10.1029/98JC02622

CAIRES S. STERL A (2003). Validation of ocean wind and wave data using triple collocation. Journal of Geophysical Research, Vol. 108(C3), 3098, 16 p. doi:10.1029/2002JC001491

CAMUS P. VIDAL C., MÉNDEZ F.J., ESPEJO A., IZAGUIRRE C, GUTIÉRREZ J.M., COFIÑO A., SAN-MARTÍN D., MEDINA R. (2007). A methodology to evaluate wave energy resources in shallow waters. Proc. $7^{\text {th }}$ European Wave and Tidal Energy Conference. ISBN: 978-989-95079-3-7. September, 2007, 10 p. 
Thème 6 - Energies marines

CAMUS P., VIDAL C., MÉNDEZ F.J., ESPEJO A., REGUERO B.G. (2009). A new methodology to evaluate wave energy resources in intermediate depths. Application to the Asturias coast (North Spain). Proceedings EWTEC 2009. Uppsala, Suecia, September 2009, 9 p.

CAMUS P. (submitted). Analysis of clustering and selection algorithm for the study of multivariate wave climate.

FRANKE R. (1982). Scattered data interpolation: test of some methods. Math. Comp., 38, pp 181-200. doi:10.2307/2007474

HOGBEN N., LUMB F. (1967). Ocean Wave Statistics. National Physical Laboratory, HMSO. London. UK.

IH CANTABRIA (2010). Evaluación del potencial de energía de las olas en España para la elaboración del Plan de Energías Renovables 2011-2020. IH Cantabria Report.

JARDINE T.P. (1979). The reliability of visually observed wave heights. Coastal Engineering 3. pp 33-38. doi:10.1016/0378-3839(79)90003-6

RIPPA S. (1999). An algorithm for selecting a good value for the parameter $c$ in radial basis function interpolation. Adv. Comput. Math. 11, pp 193-210. doi:10.1023/A:1018975909870

SOARES C., WEISSE R., CARRETERO J.C., ALVAREZ E. (2002). A 40 Year Hindcast of Wind, Sea Level and Waves in European Waters. Proceedings OMAE. 21sth International Conference on Offshore Mechanics and Arctic Engineering. OMAE2002-28604.

TOLMAN H.L. (1997). User manual and system documentation of WAVEWATCH-III version 1.15. NOAA / NWS / NCEP / OMB Technical Note 151, 97 p.

TOLMAN H.L. (1999). User manual and system documentation of WAVEWATCH-III version 1.18. NOAA / NWS / NCEP / OMB Technical Note 166, 110 p.

VIDAL PASCUAL C. (1986). Análisis de la energía del oleaje en las costas españolas. Revista de Obras Públicas, 3244, pp 95-108. 